\title{
Review of Capacitive Touchscreen Technologies: Overview, Research Trends, and Machine Learning Approaches
}

\author{
Hyoungsik Nam *D, Ki-Hyuk Seol, Junhee Lee, Hyeonseong Cho and Sang Won Jung \\ Department of Information Display, Kyung Hee University, Seoul 02447, Korea; seol8118@khu.ac.kr (K.-H.S.); \\ jklopp1007@khu.ac.kr (J.L.); chohs0713@khu.ac.kr (H.C.); mrswjung@khu.ac.kr (S.W.J.) \\ * Correspondence: hyoungsiknam@khu.ac.kr; Tel.: +82-2-961-0925
}

check for updates

Citation: Nam, H.; Seol, K.-H.; Lee, J.; Cho, H.; Jung, S.W. Review of Capacitive Touchscreen Technologies: Overview, Research Trends, and Machine Learning Approaches. Sensors 2021, 21, 4776. https:// doi.org/10.3390/s21144776

Academic Editor: Paweł Pławiak

Received: 4 June 2021

Accepted: 12 July 2021

Published: 13 July 2021

Publisher's Note: MDPI stays neutral with regard to jurisdictional claims in published maps and institutional affiliations.

Copyright: (C) 2021 by the authors. Licensee MDPI, Basel, Switzerland. This article is an open access article distributed under the terms and conditions of the Creative Commons Attribution (CC BY) license (https:/ / creativecommons.org/licenses/by/ $4.0 /)$.
Abstract: Touchscreens have been studied and developed for a long time to provide user-friendly and intuitive interfaces on displays. This paper describes the touchscreen technologies in four categories of resistive, capacitive, acoustic wave, and optical methods. Then, it addresses the main studies of SNR improvement and stylus support on the capacitive touchscreens that have been widely adopted in most consumer electronics such as smartphones, tablet PCs, and notebook PCs. In addition, the machine learning approaches for capacitive touchscreens are explained in four applications of user identification/authentication, gesture detection, accuracy improvement, and input discrimination.

Keywords: touchscreen; capacitive; display; SNR; stylus; machine learning

\section{Introduction}

Human beings collect a lot of information through their eyes, and many displays around us play a key role to transfer this visual information. Displays have evolved dramatically from cathode-ray tube (CRT) [1-4] via plasma display panel (PDP) [5-10] and liquid crystal display (LCD) [11-15] to cutting-edge organic light-emitting diode (OLED) [16-22] and micro-LED technologies [23-28]. This evolution has led to larger screen-size, slimmer design, lower weight, higher resolution, faster frame rate, brighter luminance, wider color gamut, longer life time, and lower power consumption in the large-size display applications such as monitors, televisions (TVs), and digital signage [29-39]. The resolutions of off-the-shelf displays have increased up to $8 \mathrm{~K}(7680 \times 4320)$ along with the high frame rate of $120 \mathrm{~Hz}$ and the larger screen sizes than 55-inch have taken more than $30 \%$ of overall TV set sales [40,41]. Even rollable OLED TVs were demonstrated in the consumer electronics show 2018 (CES2018) [42]. On the other side of the small-size display applications, higher density of pixels, narrower bezel, flexibility, bendability, rollability, and low power consumption have been achieved along with enhanced picture quality [43-48]. The latest smartphones contain the bezel-less screens of larger pixel densities than 450 pixel per inch (ppi) and smartphones with foldable displays are being sold on the market [49]. Recently, as augmented reality and virtual reality (AR/VR) attract substantial interest, the demand for high-performance near-eye displays is increasing further [50-57]. Consequently, the very high resolution OLED on silicon (OLEDoS) displays up to 4410 ppi have been reported [58-63].

On top of the role of a visual information provider, displays have supported the interaction with users by means of various user interfaces. Users can adjust the visual information on the screen by themselves. The very old but still popular representative user interfaces are mouse and keyboard [64-66]. There have also existed pen tablets for more elaborate works such as drawing and writing [67-70]. Because these devices work on the different planes separated from displays, additional markers such as cursors and pointers are needed. On the other hand, more intuitive input interfaces called touchscreens have been studied to directly interact with displays by touching displays [71-74]. Touchscreen technologies can be categorized into finger-touch and stylus-touch methods. While finger-touch methods 
include resistive, capacitive, acoustic wave, and optical approaches [75-101], stylus-touch ones cover up to electromagnetic resonance (EMR) schemes including finger-touch methodologies [102-108]. Recently, as wearable devices such as smartwatches and smartbands are becoming more popular, small-size displays are becoming further widespread with touch sensing functionality. However, because this very small-area screen cannot support multiple finger-touches and the whole area is covered even by a single finger, a variety of separate input modalities in the outside of the screen have been studied by using infrared (IR) line sensors, microphones, gaze trackers, IR proximity sensors, electric field sensors, deformation sensors, magnetic field sensors, and mechanical interfaces [109-123]. In addition, some approaches have coped with the limitation of the single touch by differentiating palm and finger or identifying pad, nail, tip, and knuckle of a finger [124,125]. Especially, because AR/VR displays are placed near to eyes, it is impossible to touch the screen directly. Therefore, other input tools using various sensors such as leap motion sensors, electromyograph sensors, inertial measurement units, eye-trackers, IR facial gesture sensors, cameras, and axis-tilt sensors, have been employed [126-134].

There have been also efforts to integrate machine learning (ML) approaches into touchscreen technologies. These ML networks are employed to add extra input tools, to improve the touch-sensing performance, to support the user identification/authentication, to discriminate finger-touches from others, and to capture the gestures [135-164].

There have been brief reviews of touchscreen technologies [76,96]. Walker [165] published many overview papers about a variety of touchscreen technologies from resistive to optical and electromagnetic resonance (EMR) stylus schemes. Those papers explained their histories, principles of operation, pros and cons, and applications. However, the technological details have not been handled such as algorithms, driving circuits, and ML approaches. Kwon et al. [166] reviewed capacitive touchscreen technologies including sensors, driving circuits, sensing methods, and stylus schemes in more detail. However, ML approaches were not introduced. Bello et al. [164] summarized ML approaches to improve security on touchscreen devices without addressing the touchscreen technologies. A variety of ML applications only for the security issues were addressed. This paper provides a unified and broader view of the touchscreen technologies with the detailed explanation and ML approaches in various scenarios.

The contributions of this paper are as follows:

- Providing the most comprehensive review about the touchscreen technologies. In particular, this describes various studies on sensing methods and ML approaches.

- Supplementing capacitive touchscreen techniques of the previous review paper [166] by focusing on research topics and results.

- Including various ML methods for user identification/authentication, gesture detection, accuracy improvement, and input discrimination.

- Proposing future directions for researches on touchscreen technologies integrated with ML networks.

This paper is organized as follows. Section 2 addresses the overview of the touchscreen technologies, and then Section 3 describes various studies on capacitive touchscreen applications that are integrated in most smartphone and notebook displays. Section 4 shows the ML approaches working with existing capacitive touchscreen technologies. Section 5 concludes this paper with some suggestions of the future directions.

\section{Overview of Touchscreen Technologies}

In this section, touchscreen technologies for finger as well as stylus have been simply addressed in terms of principles of operation, advantages, and drawbacks. We categorize the touchscreen technologies into four categories of resistive, capacitive, acoustic wave, and optical, and address further various techniques in each category as shown in Figure 1. Table 1 compares their specifications. 


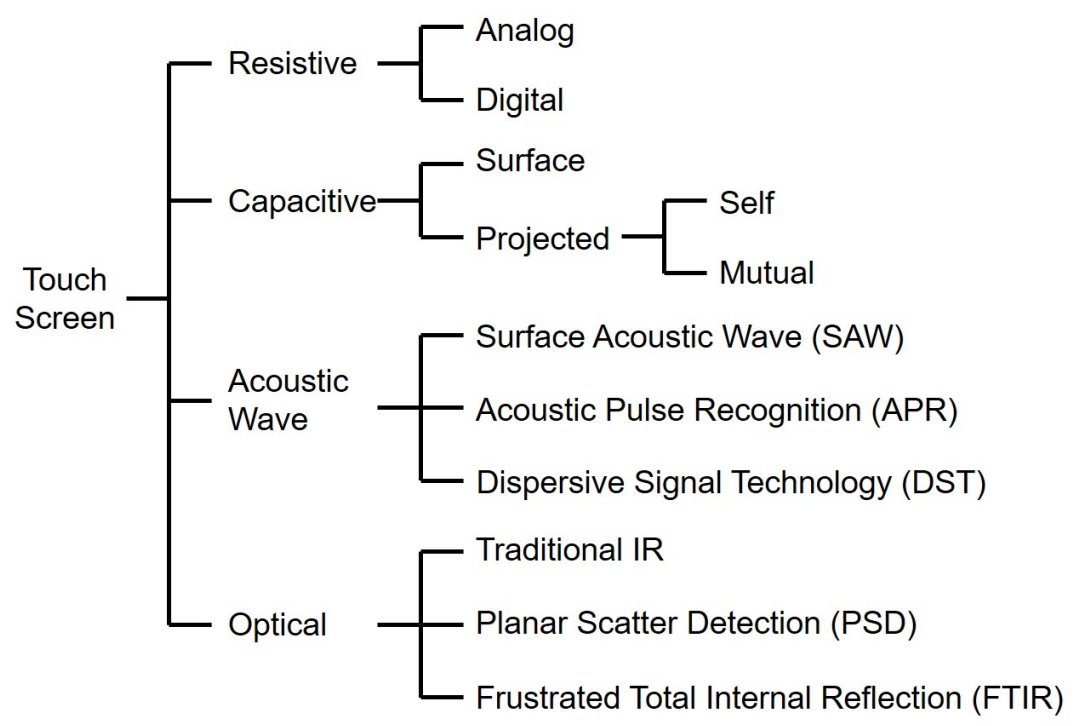

Figure 1. Categories of touchscreen technologies. This figure excludes the touchscreen techniques embedded in pixel areas in a display panel.

Table 1. Comparisons of touchscreen technologies.

\begin{tabular}{|c|c|c|c|c|}
\hline Category & Resistive & Capacitive & Acoustic & Optical \\
\hline \# Layers & 2 & 2 & 1 & $\begin{array}{l}0 \text { (Traditional) } \\
1 \text { (PSD, FTIR) }\end{array}$ \\
\hline $\begin{array}{c}\text { Touch } \\
\text { Diversity }\end{array}$ & High & Low & Average & High \\
\hline $\begin{array}{l}\text { Image Clarity } \\
\text { (Transmittance) }\end{array}$ & $75-85 \%$ & $85-90 \%$ & $92-\%$ & 88-\% \\
\hline $\begin{array}{l}\text { Multi- } \\
\text { Touch }\end{array}$ & $\begin{array}{l}\text { No (Analog) } \\
\text { Yes (Digital) }\end{array}$ & $\begin{array}{c}\text { No (Surface, Self) } \\
\text { Yes (Mutual) }\end{array}$ & No & $\begin{array}{l}\text { No (Traditional) } \\
\text { Yes (PSD, FTIR) }\end{array}$ \\
\hline Durability & Poor & Good & Best & Best \\
\hline $\begin{array}{l}\text { Computational } \\
\text { Power }\end{array}$ & Low & Average & High & $\begin{array}{l}\text { Low (Traditional) } \\
\text { High (PSD, FTIR) }\end{array}$ \\
\hline Dimension & Small & $\begin{array}{c}\text { Small (ITO) } \\
\text { Large (Metal Mesh) }\end{array}$ & Large & Large \\
\hline $\begin{array}{l}\text { Touch/Tap } \\
\text { Force }\end{array}$ & Strong & Light & Average & Light \\
\hline $\begin{array}{l}\text { Resistance to } \\
\text { Contaminants }\end{array}$ & Best & Poor & Good & Good \\
\hline $\begin{array}{l}\text { Holding } \\
\text { Function }\end{array}$ & Yes & Yes & $\begin{array}{c}\text { Yes (SAW) } \\
\text { No (APR, DST) }\end{array}$ & Yes \\
\hline $\begin{array}{c}\text { Mounting } \\
\text { Dependency }\end{array}$ & No & No & $\begin{array}{c}\text { No (SAW) } \\
\text { Yes (APR, DST) }\end{array}$ & No \\
\hline
\end{tabular}

\subsection{Resistive Touchscreen}

An analog resistive scheme is the oldest touchscreen technology [165]. It extracts touch coordinates by sampling the voltage at the touched area. The voltage is proportional to the location of the screen due to the voltage division based on the ratio of resistances from the current position to two opposite sides [78]. The most popular resistive touchscreen panels are fabricated by 4 -wire and 5-wire architectures [79]. Both methods estimate x-axis and $y$-axis coordinates of a touch position sequentially. Normally, two separate layers are coated by the conductive films only at one side, and one layer should be composed of a 
flexible material. When the touch force is applied, the flexible layer is pressed to contact the other layer and to obtain the voltage at the contacted area. Four-wire structures use both layers to generate the voltage slopes as well as to sense the voltage as illustrated in Figure 2a. For example, after the flexible layer (Layer \#1) generates the voltage slope at an $x$-axis and the other (Layer \#2) senses the voltage, Layer \#2 generates the voltage slope at an y-axis and Layer \#1 senses the voltage. Five-wire ones apply voltages only to one specific layer (Layer \#2) and use the other layer (Layer \#1) only to sense the voltage as depicted in Figure 2b. Therefore, it is known that 5-wire schemes usually have a longer life time.

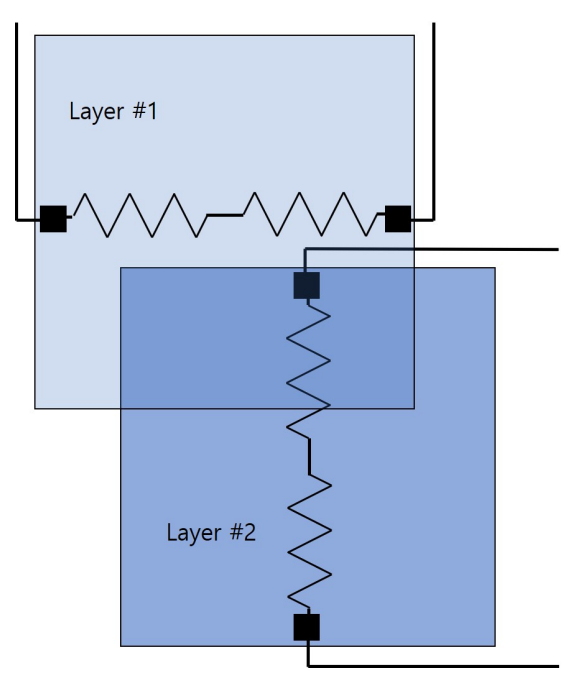

(a)

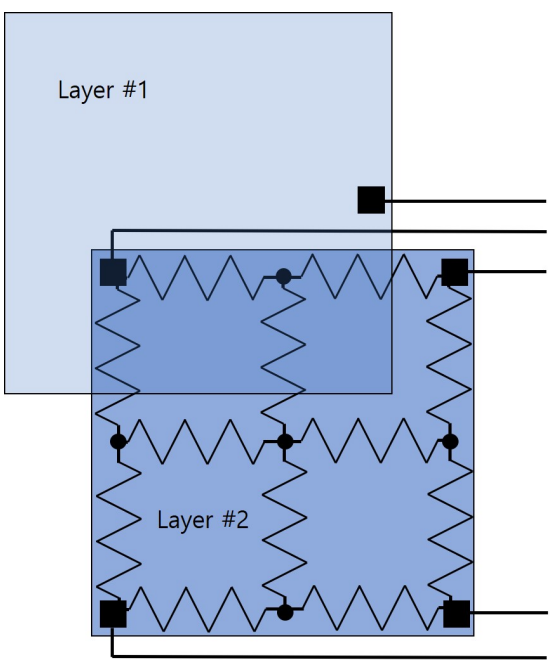

(b)

Figure 2. Two most popular resistive touchscreen architectures. (a) Four-wire. (b) Five-wire.

The advantages of the resistive touchscreen technology are to be able to work with anything, to be fabricated at the lowest cost, to be insensitive to any contaminants, and to consume low power. However, it has drawbacks of the only single touch support, the poor durability due to scratches, poking, and sharp objects, the poor optical clarity, and the relatively high touch force requirement $[80,165]$.

On the other hand, there have been efforts to support multi-touch capability. Some researchers were trying to add the multi-touch functionality to a conventional structure by sensing the current consumption at voltage sources [167-169]. Whereas, other researchers divide the conductive films into multiple lines and columns that give rise to many separate overlapped areas [170-172], where each area can detect touches separately. This scheme is named as the digital resistive touchscreen [165]. Since the resistive touchscreen methods fall short of the capacitive schemes, the resistive touchscreen panels are being applied to the limited areas such as toys, office electronics, and card payment machines.

\subsection{Capacitive Touchscreen}

Capacitive touchscreens sense the change of the capacitance caused by the finger to estimate the touch position. While resistive schemes need the pressing force to make the actual contact between two conductive layers, capacitive methods can obtain the capacitance change just by the light touch on the screen. Consequently, it enables the smooth and fast scrolling, high durability, and excellent optical performance. In addition, any materials can be adopted for layers, for example, glasses and plastics, while resistive technologies require one flexible layer at least. Because the parasitic capacitance added by fingers is very small, large-size capacitive touchscreen panels are very difficult to implement and contaminants such as water and dusts can be also recognized as touches. Recently, the large size capacitive touchscreens have been reported based on the metal 
mesh structure [108,173]. It can support only capacitive input tools including fingers to make parasitic capacitors with electrodes of the touchscreen panel.

The capacitive scheme is divided into surface-capacitive $[81,83]$ and projected-capacitive methods $[82,84]$. Surface-capacitive touchscreens consist of one conductive layer of which four corners are connected to four perfectly synchronized alternative current (AC) voltage signals as described in Figure 3. While any difference does not occur without touches at these voltage sources, the finger touching the screen brings out the current difference in four voltage sources. As the voltage source is located nearer to the touch point, the current variation becomes larger due to the smaller resistive load. As a result, the touch locations are extracted from the ratio of the currents over four voltage sources. Even though it cannot deal with multiple touches at the same time, its high durability enables the integration in automated teller machines (ATMs).

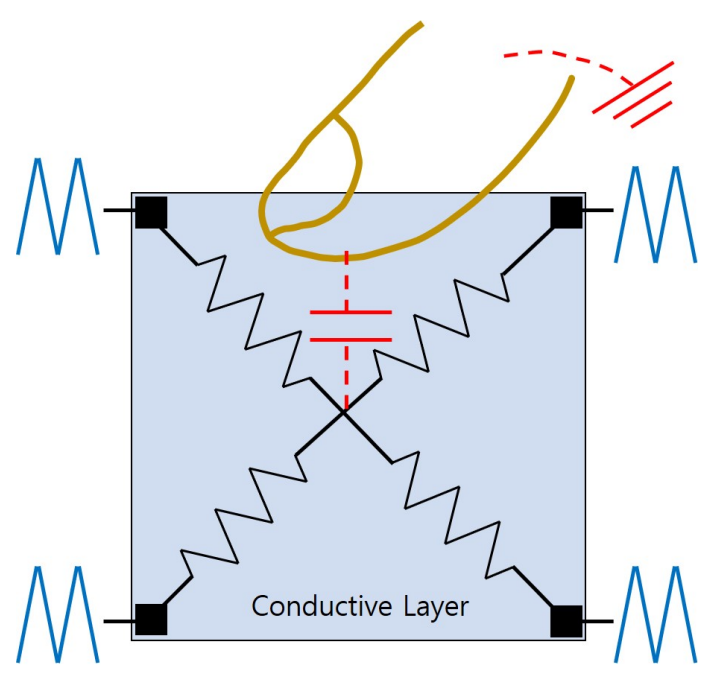

Figure 3. Surface-capacitive touchscreen. The touch location can be estimated from the current variation at four corner AC voltage sources caused by the finger touch.

The projected-capacitive methods can be further divided into self-capacitance and mutual capacitance architectures. Especially, the mutual capacitance has been the mainstream technology used in most consumer electronics such as smartphones, tablet PCs, and notebook PCs since the appearance of iPhones in 2007, because it can support multi-touch functions along with high durability and good optical clarity.

In general, the projected-capacitive touchscreen panels use two patterned conductive layers that are separated and crossed to each other in the shape of a matrix. Horizontal and vertical patterns correspond to the position information of the touch event. While the self-capacitance senses the capacitance between layers and ground as shown in Figure 4a, the mutual capacitance measures the capacitance at the overlapped areas of horizontal and vertical patterns as presented in Figure 4b. Consequently, the finger touch increases the selfcapacitance due to the additional parasitic capacitor in parallel and decreases the mutual capacitance due to the electric field loss by the finger placed between two electrodes.

The self-capacitance estimates $\mathrm{x}$-axis and $\mathrm{y}$-axis coordinates sequentially by measuring the capacitance of vertical and horizontal electrodes over the ground, respectively. Consequently, the multiple touches may cause ghost touches. For example, when there are two touches at locations of $(x 1, y 1)$ and $(x 2, y 2)$, the self-capacitance can figure out that there are touches at $\mathrm{x} 1, \mathrm{x} 2, \mathrm{y} 1$, and $\mathrm{y} 2$, separately, and then it provides two correct locations of $(x 1, y 1)$ and $(x 2, y 2)$ along with two additional ghost locations of $(x 1, y 2)$ and $(\mathrm{x} 2, \mathrm{y} 1)$ by four possible combinations of two $\mathrm{x}$-axis data and two $\mathrm{y}$-axis data. Thus, the self-capacitance has difficulty to support multi-touch functionality. To cope with this ghost touch issue, some panel makers use separate self-capacitance cells directly connected to the touchscreen controller that senses each capacitance variation, respectively, [174]. This approach has been implemented in the off-the-shelf smartphones. 

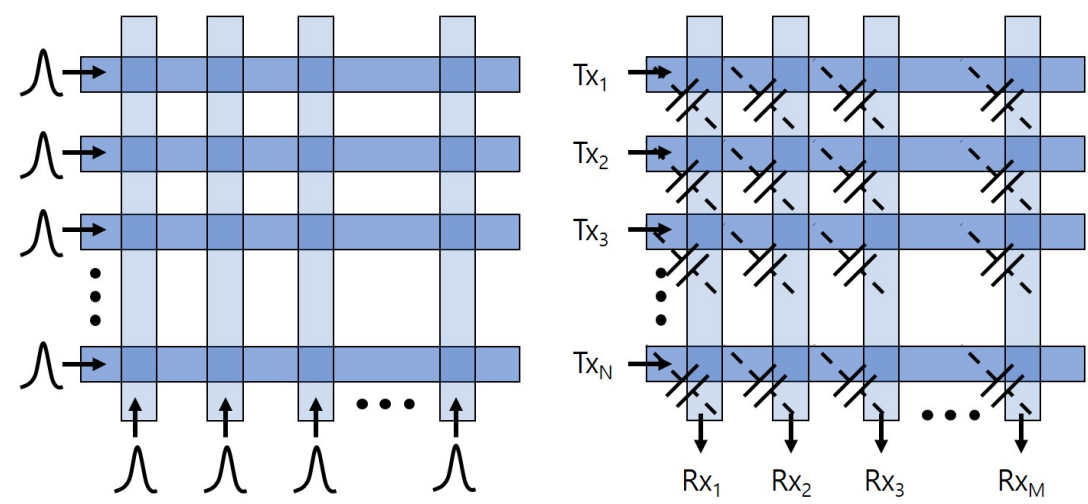

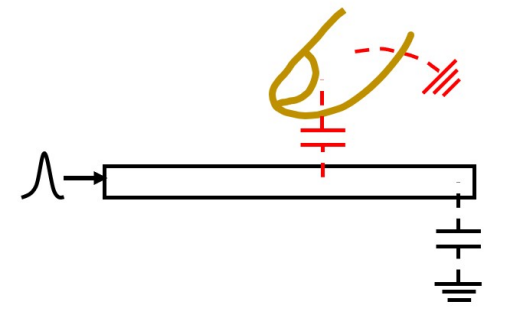

(a)

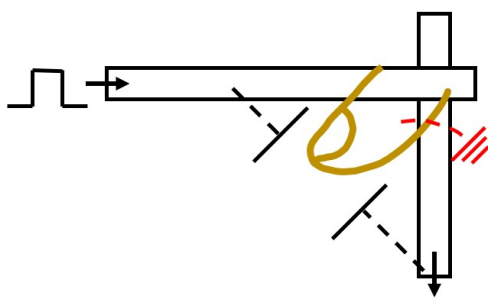

(b)

Figure 4. Projected-capacitive methods. (a) Self-capacitance. (b) Mutual capacitance.

On the other hand, because the mutual capacitance measures the overlap capacitance separately between vertical and horizontal conductive patterns, it can support multi-touch functions without any limits on the number of fingers. Therefore, it has become the widely used touchscreen technology today. The excitation pulses are applied to horizontal patterns and the transferred charges are measured through charge amplifiers at the ends of the vertical patterns. Since the amount of transferred charges is proportional to the mutual capacitance, the variation of capacitance can be detected. Section 3 will address the mutual capacitance approaches in more details.

While additional touchscreen panels on the displays require further electronics, the embedded touchscreen solutions that are called an in-cell touch can merge panel and touchscreen electronics into a single driver integrated circuit. Therefore, various in-cell approaches have been developed including self-capacitance cells and capacitive sensors embedded in pixel areas [174-179].

\subsection{Acoustic Wave Touchscreen}

The acoustic wave scheme is composed of a wave guide, sound wave sources, and receivers. The well-known technology is a surface acoustic wave (SAW) touchscreen as depicted in Figure $5[85-87,91]$. The SAW contains two pairs of ultrasonic transmitters and receivers to calculate $\mathrm{x}$-axis and $\mathrm{y}$-axis coordinates of touch locations, respectively. The reflectors in the bezel area generate multiple horizontal and vertical acoustic wave paths that have different arrival times at receivers. When a finger is placed in a certain path, the signals attenuated by that touch arrive at the receiver with corresponding delays that are converted into the position coordinates. Because the SAW needs only one wave guide layer, it has the most excellent optical performance. In addition, large size touchscreen and high durability are achievable. However, its sequential estimation of $\mathrm{x}$-axis and $\mathrm{y}$-axis coordinates gives rise to the same ghost touches as the self-capacitance method. It can also detect some input tools of soft materials to absorb waves and the sensing performance is sensitive to contaminants on the screen. 

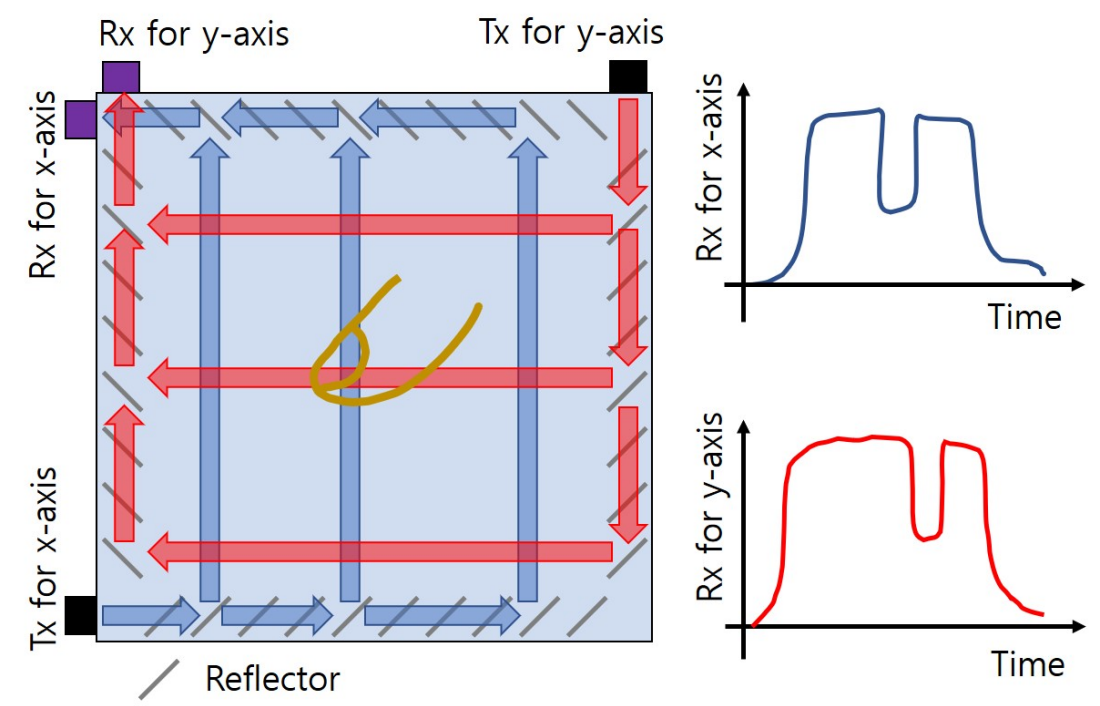

Figure 5. Surface acoustic wave (SAW) touchscreen. The ultrasonic waves move through multiple horizontal and vertical paths. The finger touch attenuates the received signal strength in the contacted wave paths and their delay information is converted to the touch locations.

The another one is a bending wave scheme, where the sound wave caused by tapping on the screen is used as the sound source as well as the touch signal $[88,89,89,90]$. There are two methods of acoustic pulse recognition (APR) and dispersive signal technology (DST) [180]. The APR senses the bending waves by multiple piezoelectric transducers and processes them with the data stored in the memory to extract the touch positions. Therefore, the APR needs a prior process to sample and store the large amount of bending wave data at enough number of positions over the screen. However, because the bending wave characteristics are not deterministic, the resultant coordinates have some variance, leading to errors on the location estimation. Furthermore, the enough bending wave strength is required for the sensors to detect. The bending wave characteristics are dependent of the mounting structure and material. Since too large an amount of data is necessary for multi-touch cases, it supports only a single-touch input.

To cope with the requirement of the prior process to store the bending wave data in the APR, the DST extracts touch locations directly only from the measured bending wave data. Because the signal delay is affected by its frequency, the measured time and frequency information is used to reconstruct the bending wave pattern on the screen, which is converted to the touch coordinates. However, it also has several drawbacks such as only single touch support, high tapping strength, measurement variance, mounting dependency, as well as high computational power. In addition, both APR and DST cannot support the holding function because only the tapping action generates the sound waves.

\subsection{Optical Touchscreen}

The optical touchscreens are developed based on the invisible infrared (IR). The traditional IR-based touchscreen places transmitters at two sides and receivers at their opposite sides without any additional layers. Because the touches block the light path over the screen between a pair of transmitter and receiver, $x$-axis and $y$-axis coordinates can be obtained by finding the receivers' positions that do not receive IR. While large-size displays and excellent optical clarity can be supported, the bezel needs some height over the screen for IR transmitters and receivers and the multiple touches cause the ghost touch issue.

The other IR-based schemes such as planar scatter detection (PSD) $[100,101]$ and frustrated total internal reflection (FTIR) $[75,95,98,99]$ are similar to the acoustic wave approaches except for the use of IR instead of the sound wave. In the PSD, while the transmitters send the IR lights through the wave guide at the total internal reflection (TIR) condition, receivers sense them. When any touches are applied on the wave guide plate, it 
breaks the TIR condition out, therefore, the scattered and remaining TIR lights arrive at multiple receivers as described in Figure 6a, leading to the extraction of the touch location by the complex analysis. The PSD can support multi-touch and high image clarity, but the larger-size touchscreens require higher computational power to extract the touch location. The FTIR also makes use of the TIR condition, but the touch location is attained from the lights escaped toward the opposite plane to the touched one as depicted in Figure $6 \mathrm{~b}$. Those lights are captured by the external camera or vision sensors and the resultant images provide the information of touch locations. There also exist the embedded LCD solutions, where IR transmitters are allocated in the backlight and the vision sensors are placed in the pixel areas.

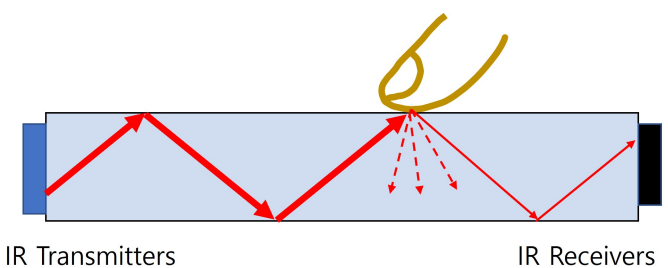

(a)

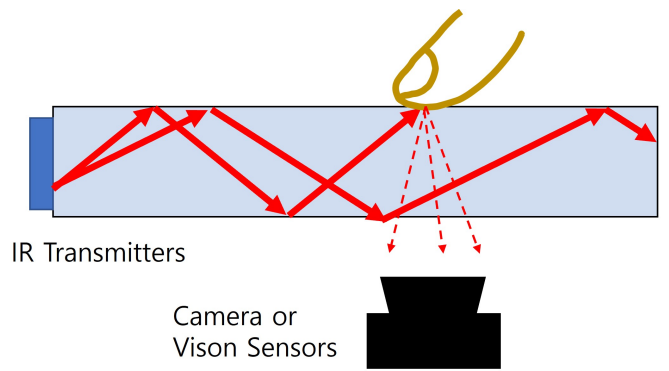

(b)

Figure 6. TIR-based IR touchscreen technologies. (a) PSD. (b) FTIR.

\section{Main Research Trends in Mutual Capacitance Capacitive Touchscreen Technologies}

As explained in the previous section, there have exist various touchscreen technologies by means of resistance, capacitance, sound wave, and IR. Among them, the capacitive touchscreen has become a mainstream scheme, especially, the mutual capacitance touchscreen is the most widely used technology on many consumer electronics such as smartphones, notebook PCs, tablet PCs, and smartwatches, because of its multi-touch support, slim form factor, high optical quality, excellent durability, smooth scrolling, and so on. Particularly, this section addresses the mutual capacitance capacitive touchscreens in more details. Unlike the self-capacitance method where the parasitic capacitor of a finger touch is connected to the self-capacitor in parallel, the mutual capacitance scheme experiences the capacitance reduced by electric field leakages into a finger. As a result, the touch location can be found out by searching the position which mutual capacitance is reduced.

As shown in Figure 7, a conventional mutual capacitance capacitive touchscreen panel is composed of excitation (EX) electrodes and sensing (SE) electrodes, which give rise to the mutual capacitor array at their intersection areas [181,182]. Excitation drivers generate EX pulses sequentially in the way of line-by-line that arrive at charge amplifiers attached to SE lines through mutual capacitors. The non-inverting input terminals of these charge amplifiers are connected to the reference voltage $\left(V_{R E F}\right)$ and the charge transferred through a mutual capacitor $\left(C_{m}\right)$ is converted through a feedback capacitor $\left(C_{f}\right)$ into analog voltages $\left(V_{O U T}\right)$ that are proportional to the mutual capacitance as presented in Equation (1). $V_{E X}$ is the amplitude of the EX pulse. When a user touches on the screen with a finger, the reduction on the mutual capacitance is sensed as the different output voltage of the charge amplifier from the voltage level obtained without any touches as illustrated in Figure 8 . To 
improve the precision of the touch detection, the transferred charge is accumulated at the charge amplifiers over multiple EX pulses. In addition, a multiplexer (MUX) allows one analog-to-digital converter (ADC) to sample the output voltages of charge amplifiers in all SE lines sequentially. Finally, a host processor handles the digital data to determine the touch locations and it also controls excitation drivers.

$$
V_{\text {OUT }}=V_{R E F}-\frac{C_{m}}{C_{f}} V_{E X}
$$

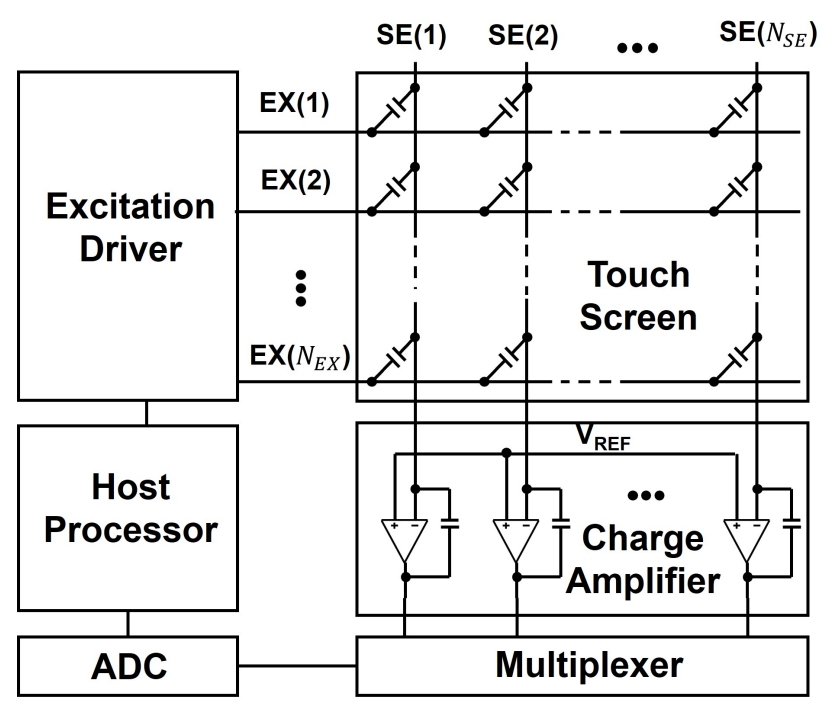

Figure 7. Block diagram of a conventional mutual capacitance capacitive touchscreen system. $N_{E X}$ and $N_{S E}$ are the numbers of excitation and sensing electrodes, respectively. The touch locations are estimated from the mutual capacitor array formed at the intersection areas of EX and SE lines.

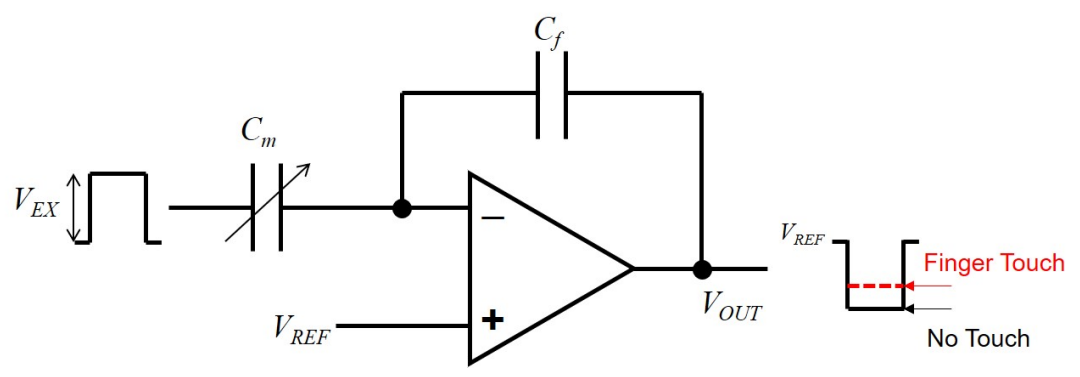

Figure 8. Charge amplifier circuit. The change of $C_{m}$ causes different output voltage levels ( $\left.V_{\text {OUT }}\right)$.

The mainstream studies in mutual capacitance schemes are (a) improving signalto-noise ratio (SNR) to achieve higher accuracy as well as robustness over the noises and (b) utilizing additional input tools such as styli besides fingers. In addition, it is another research trend to integrate the pressure-sensing capability. However, the most approaches support this pressure sensing function through additional sensors [183,184], the separation distance changes $[185,186]$, or the internal circuit of the stylus $[108,187]$. Because additional sensors and separation distance changes are out of this review's scope, the stylus technologies are addressed along with their pressure sensing schemes.

\subsection{SNR Improvement}

For the SNR improvement, various noises such as display noises, charger noises, and hum noises need to be addressed. Usually, the most sensing circuits employ the voltage accumulation at the output of the charge amplifier as shown in Figure 9, to suppress the noise power over the main signal, based on the assumption that the noise is independent and identically distributed [188]. Because the noise power and the signal power are propor- 
tional to the number of pulses and its squared value, respectively, the SNR improvement is achieved.

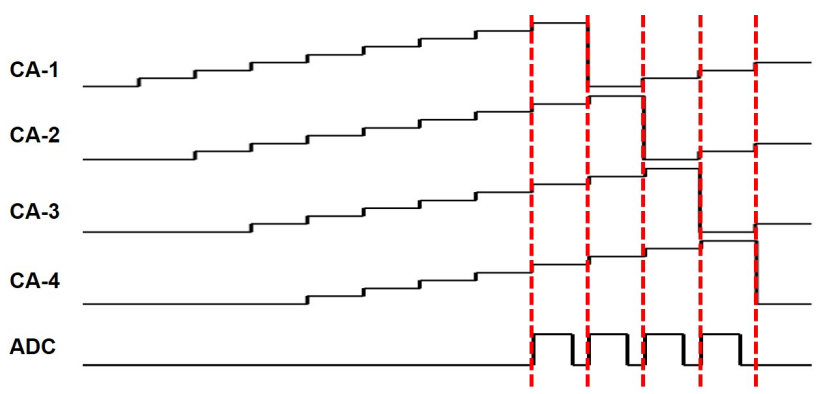

Figure 9. The SNR improvement is achieved by accumulating output pulses of charge amplifiers. CA- 1 to CA- 4 are the accumulated voltages for the outputs of four charge amplifiers. The outputs accumulated over several pulses are sampled by the ADC.

Yang et al. [189] employed the differential-ended charge amplifier with two out-ofphase excitation pulses (EX, EXb) as depicted in Figure 10. With the single-ended amplifier, the output dynamic range (DR) is limited by the default mutual capacitance without touches. However, the proposed differential structure reflected only the difference of the mutual capacitance $\left(C_{m}\right)$ over the adjacent line's capacitor on the output voltages. In addition, the differential-ended amplifier gave rise to the doubled DR by non-inverting and inverting outputs $\left(V_{\text {outp }}, V_{\text {outn }}\right)$. Therefore, the increased signal power led to the improved SNR performance.
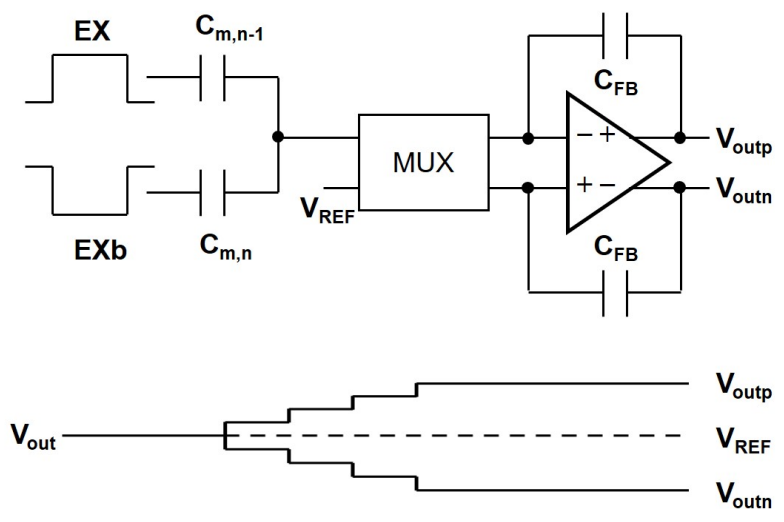

Figure 10. The dynamic range of the output voltage is enhanced by using differential-ended charge amplifier and out-of-phase excitation pulses.

Kim et al. [190] proposed the common-mode noise cancellation by subtracting the signals of the adjacent EX lines. Since the parasitic capacitance between neighboring EX lines of a touchscreen panel and display panel are almost equal, the injected noises from the display to the touchscreen would be similar, therefore, the differential sensing method over EX pulses of two neighboring lines could eliminate the common-mode display noise. Yang et al. [191] added a charge-interpolation filtered-delta-integration (CI-FDI) scheme to cancel the charger noise. The large noise is detected, and then the noise is prevented by the charge-interpolation.

As the other method to reduce the display noise components, it was proposed that the sensing operation was conducted only during the vertical blank interval as presented in Figure 11a. However, the sensing operation over the whole touchscreen area should be finished within very short period of time at the end of a frame time. Since it could not support smooth scrolling motions, the time division multiple sensing (TDMS) was introduced to spread the touch sensing functions evenly over a frame time [174,192], where 
the divided vertical blank parts were added in the middle of the active interval by stopping the scanning operations as illustrated in Figure 11b.

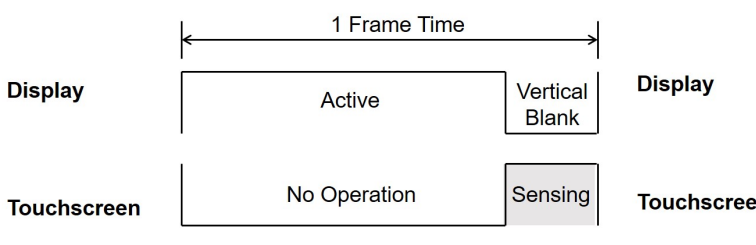

(a)

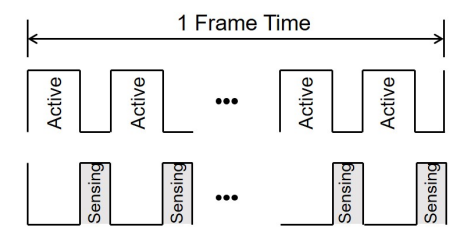

(b)

Figure 11. Touch sensing methods during the vertical blank periods. (a) Sensing during one vertical blank period. (b) TDMS sensing during divided vertical blank periods in the middle of a frame.

Miura et al. [193] adopted a two-step dual-mode scheme that performed self- as well as mutual-capacitance measurements. After the self-capacitance measurement found the touched areas, the mutual-capacitance measurement provided the fine touch location over the touched areas. Therefore, it achieved the high resolution of $80 \times 80$ and the high scan rate of $322 \mathrm{~Hz}$.

An output accumulation sensing method can improve the SNR by applying multiple EX pulses per one touch position estimation, but lowers the scan rate inevitably. To improve SNR as well as scan rate simultaneously, Shin et al. [194] implemented a code-division multiple-sensing (CDMS) method. While multiple EX pulses per one EX line are used for sensing one touch position like the output accumulation sensing method, multiple EX electrodes are excited with orthogonal patterns simultaneously as illustrated in Figure 12. Then, the touch information over multiple positions was obtained at the same time through the decoding process. As a result, the CDMS method achieves a much higher scan rate without the SNR degradation $[195,196]$.

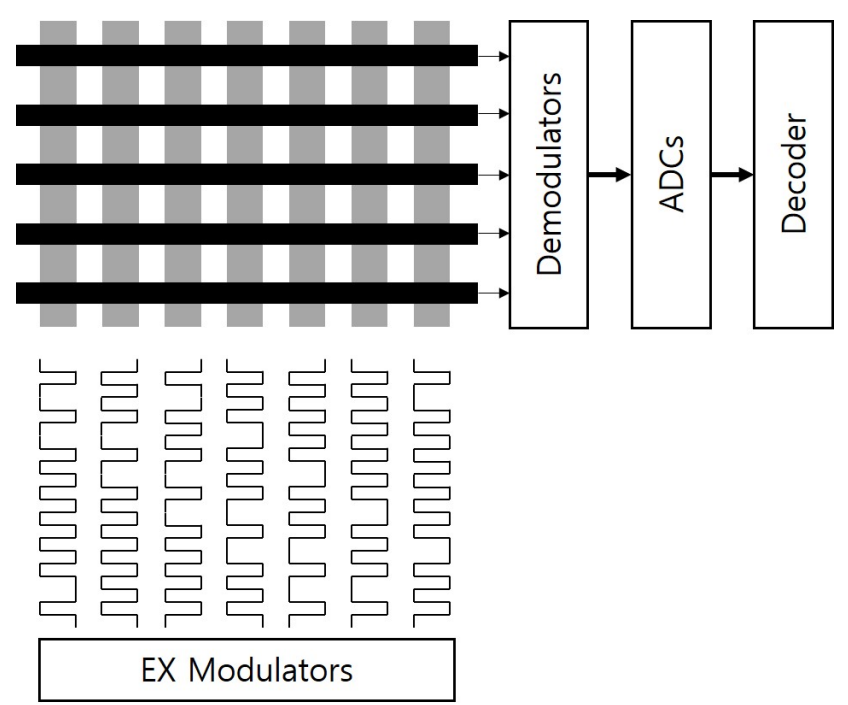

Figure 12. Code division multiple sensing. CDMS enables the multiple capacitance sensing at the same time by transmitting orthogonal codes through multiple EX lines. The charge amplifiers' outputs are demodulated and converted into digital data that are decoded as multiple simultaneous touch locations.

Park et al. [197] used the delta-sigma modulator in the ADC to move the low frequency noise to the high frequency region as shown in Figure 13. By applying a low-pass filter to remove the high frequency noise components, the noise power within the touch signal band was substantially reduced, leading to the improved SNR performance. 


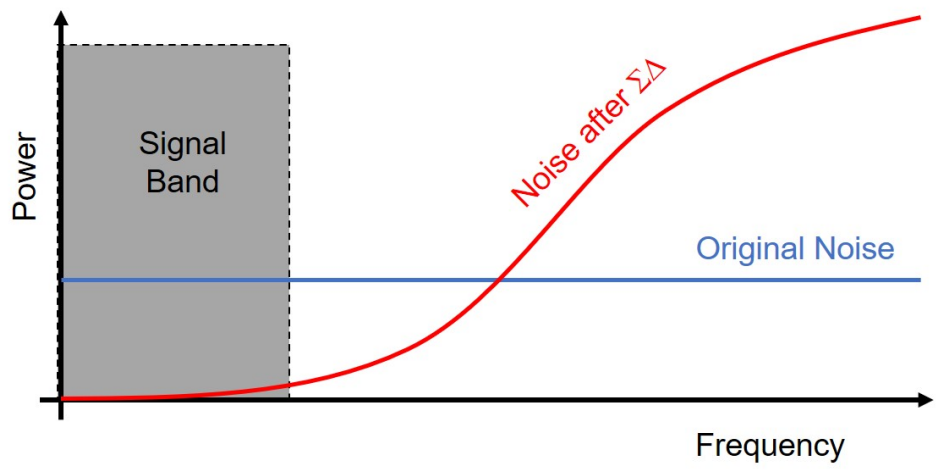

Figure 13. The sigma delta modulator shapes the noise power by moving the low frequency noises to the high frequency region. Therefore, the SNR at the signal band is improved by means of low-pass filtering.

An et al. [108] introduced the multiple-frequency driving scheme. A fast Fourier transform (FFT) was applied to find the touch locations because EX pulses had different frequencies for each EX line, that is, the number of EX frequencies is equal to the number of EX lines. Furthermore, a spectrum of external noises was acquired, and then the frequencies of EX signals were located in the low noise region for the high SNR. However, in order to implement the FFT functionality, EX signals must be driven at a very high frequency for the large number of EX lines, which leads to the increased power consumption and hardware complexity. In addition, An et al. [198] integrated the amplitude-modulation to the multiple-frequency driving scheme to reduce the charge-overflow. The excitation pulses were amplitude-modulated to reduce their amplitudes with the same periodicity. It achieved $33.9 \mathrm{~dB}$ charge-overflow reduction, leading to the high SNR performance.

The above SNR improving technologies are summarized in Table 2 including SNR, scan rate, touchscreen resolution, year, and reference.

Table 2. Specification comparison of capacitive touchscreen technologies.

\begin{tabular}{cccccc}
\hline Approach & SNR (dB) & Scan Rate $\mathbf{( H z )}$ & Resolution & Year & Reference \\
\hline Accumulation & 24 & 65 & $20 \times 16$ & 2010 & {$[188]$} \\
\hline High DR & 12.6 & 140 & $53 \times 29$ & 2011 & {$[189]$} \\
\hline Noise Cancel & 35 & 120 & $30 \mathrm{SE}$ & 2012 & {$[190]$} \\
\hline CI-FDI & 39 & 27 & $43 \times 24$ & 2013 & {$[191]$} \\
\hline CDMS & 55 & 240 & $30 \times 24$ & 2013 & {$[194]$} \\
& 72 & $32 \times 10$ & 2016 & {$[196]$} \\
\hline Dual-mode & 41 & 322 & $80 \times 80$ & 2015 & {$[193]$} \\
\hline TDMS & 52 & 120 & $80 \times 45$ & 2015 & {$[174]$} \\
\hline Noise & 40 & 6300 & $8 \times 12$ & 2014 & {$[197]$} \\
Shaping & 67 & 50 & & & \\
\hline Multiple & 61 & 3900 & $64 \times 104$ & 2017 & {$[108]$} \\
Frequency & 61.6 & 2930 & & & {$[198]$} \\
\hline & & & &
\end{tabular}

\subsection{Stylus Support}

Handwriting and drawing applications on touchscreens require more elaborate input tools than a finger. The representative input tool is a stylus that has the shape of a pen. The simplest stylus implementation called a passive stylus is based on the conductive tip that imitates a finger touch as depicted in Figure 14a [103]. However, since the contact area must be large enough to be comparable to that of a finger, it is not adequate to elaborate works. 
In addition, it cannot support smooth scrolling and high durability due to its rubber-type tip. Additionally, the passive stylus is not distinguished from a finger. Lin et al. [199] showed that the pressure level could be sensed in the passive stylus due to the contact area change of the deformable head proportional to the pressing force.

Active stylus schemes have been introduced to support elaborate works even with small-sized tips as illustrated in Figure 14b. The early active stylus [105] senses EX pulses from the touchscreen and transmits its inverted and boosted pulses back to the touchscreen via a tip. As these inverted pulses reduce the amount of charges transferred to the charge amplifiers, the resultant outputs of charge amplifiers become equivalent to the voltage levels caused by the reduced mutual capacitance. The process of amplifying the sensed EX signal allows for the use of much smaller radius tips than the passive stylus.

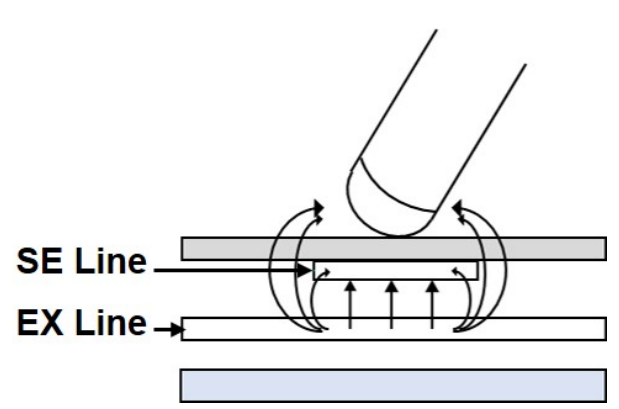

(a)

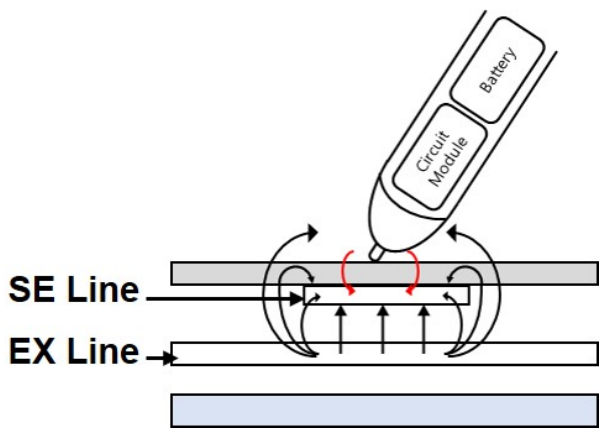

(b)

Figure 14. Stylus technologies for capacitive touchscreens. (a) Passive stylus. (b) Active stylus.

If larger inverted pulses are applied to the tip, the different output voltage from finger-touch as well as no-touch will be obtained at charge amplifiers, which enables the stylus differentiation from the finger [106]. However, this scheme needs much higher voltage amplification at stylus circuits than EX pulses of the touchscreen to give rise to the additional voltage level required for the stylus discrimination. It reduces both dynamic range and SNR for the finger-touch detection when the ADC has the fixed input voltage range. In addition, the boosted voltage levels should be separately adjusted in accordance with touchscreens.

An et al. [108] introduced the other active stylus based on the multiple-frequency driving scheme as presented in Figure 15. It could distinguish the stylus from the finger, because tip pulses of the stylus had different frequencies from EX pulses of the touchscreen. Even though it can achieve the high SNR, it required the high computational power due to the FFT implementation. Its stylus supported pressure and tilt sensing functions by means of additional force gauge and gyro sensor.

Lee et al. [187] proposed an electrically coupled resonance (ECR) stylus. As depicted in Figure 16, when the excitation pulse is asserted, the pulse is transferred to an LC resonance circuit of inductor $\left(L_{S T}\right)$ and capacitor $\left(C_{P R}\right)$ in the ECR stylus and the signal of the resonance frequency is transmitted from the tip of the stylus to the touch sensing circuits. Since the ECR stylus consists of only passive elements, it does not need any batteries. In addition, the finger touch can be differentiated from the stylus. Because $C_{P R}$ is modified by the pressure, the pressure level can be differentiated by the resonance frequency. However, the large excitation pulse amplitude is necessary to generate the resonance pulse signals that can be detected at the touch sensor circuits. Besides, the frequency detection requires the increased hardware complexity. 


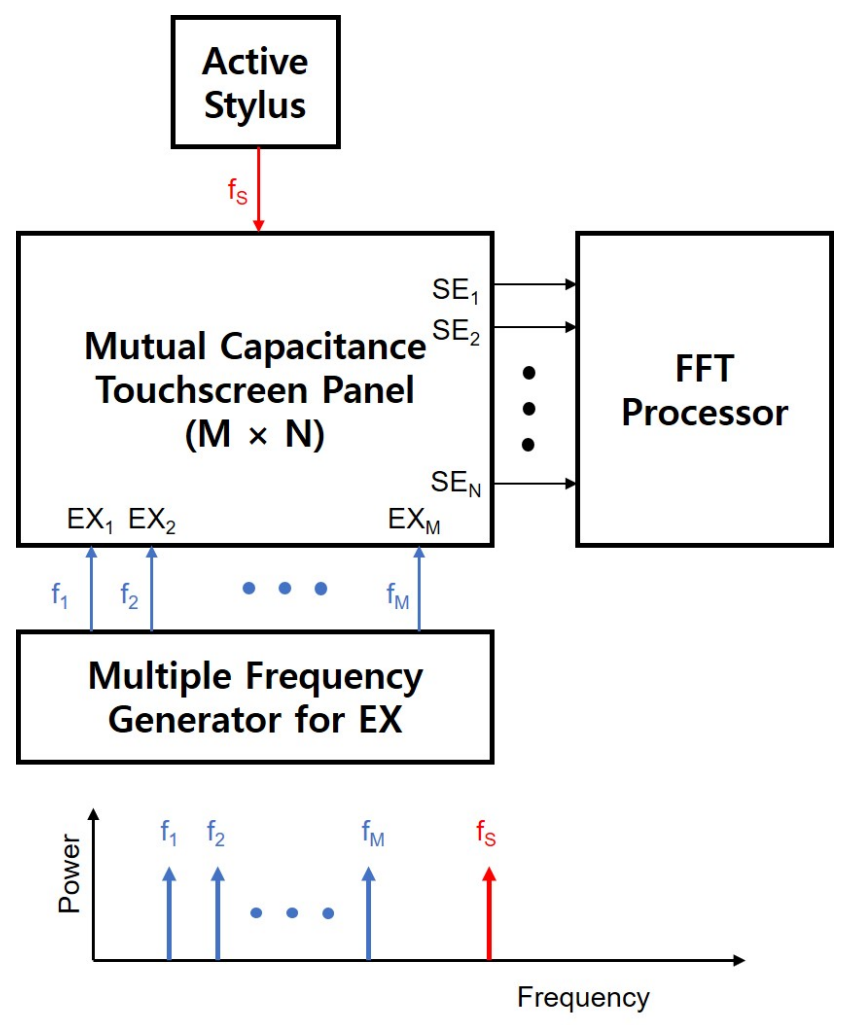

Figure 15. Multiple-frequency driving touchscreen scheme based on an FFT processor. EX lines as well as stylus can be discriminated in the frequency domain at the same time by assigning different frequencies.

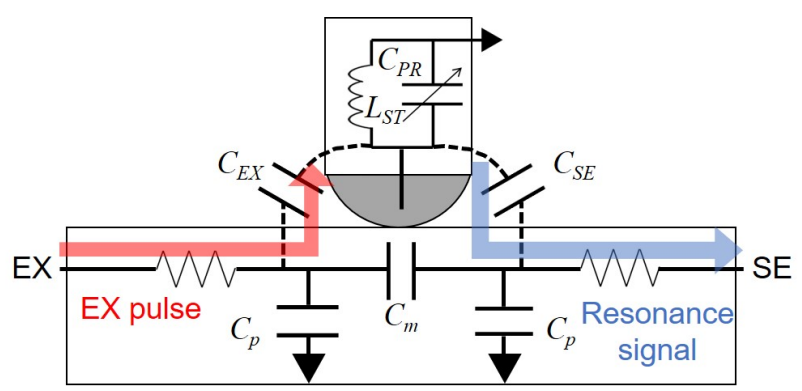

Figure 16. Electrically coupled resonance stylus. EX pulses are transmitted to the inside LC circuit and resonance signals are transferred to the coupled SE line. $C_{m}$ is the mutual capacitance, $C_{p}$ is the parasitic capacitor of EX and SE lines, $C_{E X}$ is the coupling capacitance between EX line and stylus, and $C_{S E}$ is the coupling capacitance between $S E$ line and stylus. $L_{S T}$ and $C_{P R}$ are inductance and capacitance of the resonance circuit in the stylus.

Seol et al. $[157,163]$ adopted the active stylus scheme that used the higher frequency pulses to generate different patterns from EX pulses for the finger-touch detection. It discriminated stylus-touches from no-touches and finger-touches without the high complicated FFT functionality by machine-learning-based classifiers as depicted in Figure 17. It also showed that the proposed method allowed for the effective data communication between touchscreens and styli. On the other hand, since the patterns of stylus-touches were placed in between finger-touches and no-touches, the achieved SNR was relatively low compared to the state-of-the-art high SNR touchscreen technologies. 


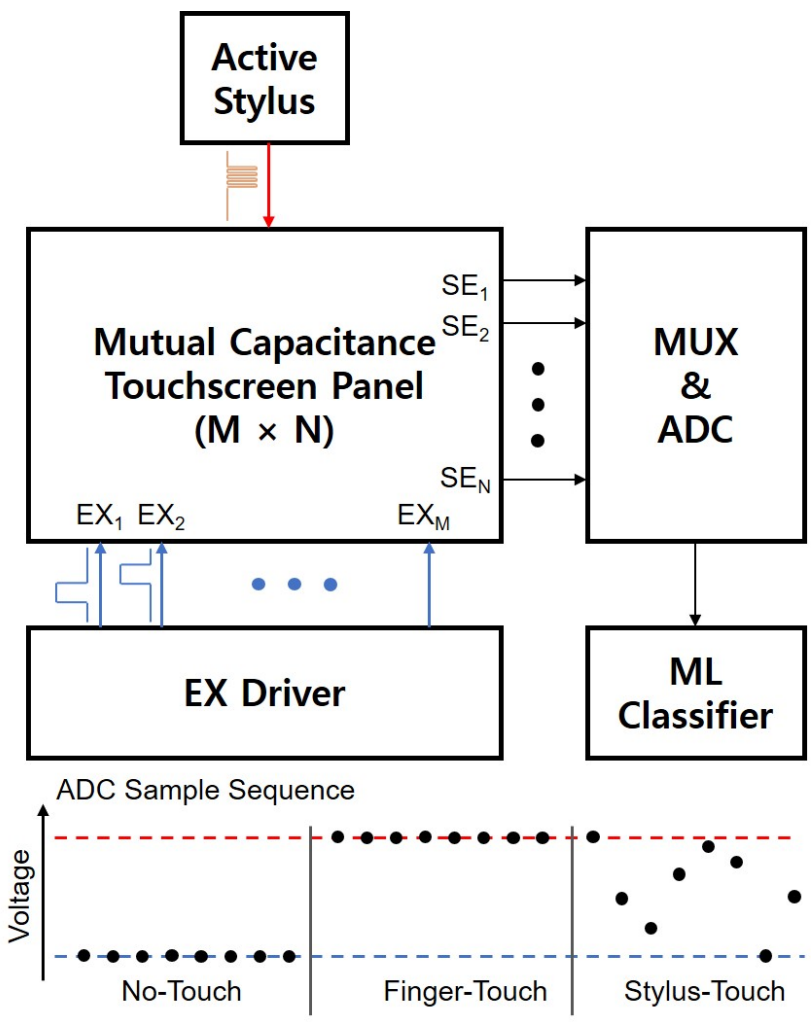

Figure 17. ML-based touchscreen scheme. The higher frequency pulses of a stylus generate the different sequence from finger-touch and no-touch, and three touches are discriminated by ML-based classifiers.

While previous passive and active ways are grounded in the capacitive touchscreen panel, there is a stylus with a different approach that works with an electro-magnetic resonance (EMR) technology [107]. Since EMR responds only to the stylus and the capacitive touchscreen panel senses only the fingers, two separate touch sensing schemes enable the finger to be distinguished from the stylus. However, this technique needs additional layers that increase hardware complexity as well as manufacturing cost.

The stylus technologies that can be implemented on the capacitive touchscreen are summarized in Table 3 in terms of tip size, stylus discrimination support, SNR degradation, computational cost, and hardware complexity.

Table 3. Comparison of stylus technologies for capacitive touchscreens.

\begin{tabular}{ccccccc}
\hline Reference & Passive & Active & FFT & ML & EMR & ECR \\
{$[103,199]$} & Large & Small & Small & Small & Small & Small \\
\hline Tip Size & No & $\begin{array}{c}\text { No }([105]) \\
\text { Yes }([106])\end{array}$ & Yes & Yes & Yes & Yes \\
\hline $\begin{array}{c}\text { Stylus } \\
\text { Discrimination }\end{array}$ & No & $\begin{array}{c}\text { No }([105]) \\
\text { Yes }([106])\end{array}$ & No & Yes & No & Yes \\
\hline $\begin{array}{c}\text { SNR } \\
\text { Degradation }\end{array}$ & Yes [199] & Low & Yes & No & Yes & Yes \\
\hline $\begin{array}{c}\text { Pressure } \\
\text { Sensing }\end{array}$ & Low & Low & High & Low & High & High \\
\hline $\begin{array}{c}\text { Computational } \\
\text { Cost }\end{array}$ & High & Low & High \\
\hline $\begin{array}{c}\text { Hardware } \\
\text { Complexity }\end{array}$ & & & & Hium & \\
\hline
\end{tabular}




\section{Machine Learning Approaches in Mutual Capacitance Capacitive Touchscreen}

Several ML algorithms have been employed to the capacitive touchscreen in a variety of applications such as user identification/authentication, gesture detection, accuracy improvement, and input discrimination. While many approaches used traditional ML techniques of decision tree (DT), random forest (RF), naive Bayes (NB), radial basis function network (RBFN), back propagation neural network (BPNN), support vector machine (SVM), and Gaussian process regression (GPR), the latest ML networks, such as convolutional neural network (CNN), anomaly detection (AD), and recurrent neural network (RNN), have been also utilized in the touchscreen field. The following machine learning applications are implemented on the off-the-shelf smartphones and tablet PCs with mutual capacitance capacitive touchscreens.

\subsection{User Identification/Authentication}

The user identification and authentication is the most active field to apply the machine learning to the touchscreen because the touch behaviors are different according to the users. Kolly et al. [135] used DT, RF, and NB classifiers over touch gestures for the user authentication application. Mean and maximal pressures, the point in the time at the maximal pressure event, minimal and maximal gradients of the pressure, the hold time, mean $\mathrm{x}$-axis and $\mathrm{y}$-axis positions, and the variances in $\mathrm{x}$-axis and $\mathrm{y}$-axis directions were employed as input features that were crowdsourced by designing a quiz game. The resultant identification accuracy for five users was $80 \%$ or more. It also proposed the anomaly detection for the user authentication based on the learned distribution of features from 5 button touch events. The equal error rate of false reject ratio (FRR) and false accept ratio (FAR) was estimated as about $30 \%$.

Feng et al. [138] proposed a finger-gesture authentication system using touchscreen (FAST). FAST collected touch gesture information including gesture type, $\mathrm{x}$-axis and $\mathrm{y}$-axis coordinates, directions of the finger motion, finger motion speed, pressure, and the distance between multi-touch points. Totally 53 features for each gesture and six gestures of down to up swipe, up to down swipe, left to right swipe, right to left swipe, zoom-in and zoom-out were put into DT, RF, and NB classifiers. It achieved FAR of $4.66 \%$ and FRR of $0.13 \%$ for the continuous post-login user authentication.

For the user authentication, Meng et al. [139] constructed 21 features such as average touch movement speeds for eight directions, fractions of touch movements for eight directions, average single-touch time, average multi-touch time, number of touch movements per session, number of single-touch events per session, and number of multi-touch events per session. They evaluated the performance of DT, NB, Kstar, RBFN, and BPNN, leading to the conclusion that RBFN showed the best performance with FAR and FRR of $7.08 \%$ and $8.34 \%$. In addition, the particle swarm optimization (PSO) with a RBFN classifier reduced FAR and FRR further to $2.5 \%$ and $3.34 \%$, respectively.

Saravanan et al. [140] proposed the authentication scheme based on the user's touch interaction with common user interface elements such as buttons, checkboxes, and sliders. Using SVM and RF, they achieved average accuracies of $97.9 \%$ and $96.79 \%$ with mobile phone and tablet PC, respectively.

Guo et al. [143] proposed CapAuth that is a user identification and authentication technique based on capacitive touchscreen data combined with machine learning classifiers. It used the capacitive image of the hands-flat pose revealing the more distinguishing features. CapAuth was built based on quadratic-kernel SVM classifiers, a binary classifier for authentication and a multi-class one-to-one classifier for identification. The measure FRR and FAR for authentication were $5.5 \%$ and $0.1 \%$, respectively. The accuracy of the identification was $94.0 \%$ for 20 users.

Rilvan et al. [148] used four fingers, thumb, as well as ear as the types of biometrics for authentication with the machine learning classifiers such as SVM and RF. It achieved the maximum authentication accuracy of $98.84 \%$ over four fingers with SVM and maximum identification accuracy of $97.61 \%$ by four fingers with RF. 
Meng et al. [152] enhanced touch behavioral authentication by cost-based classifier selection, where the best classifier with the lowest cost value was selected among a set of classifiers including DT, NB, RBFN, and BPNN. It had nine touch features such as the number of touch movements per session, the number of single-touch events per session, the number of multi-touch events per session, the average time duration of touch movements per session, the average time duration of single-touch per session, the average time duration of multi-touch per session, average speed of touch movement, average touch size, and average touch pressure. The average error rate of FAR and FRR was measured to be less than $5 \%$ for 15 sessions or more.

\subsection{Gesture Detection}

The user identification and authentication require various touch data such as location, speed, force, and gestures as features that are of the most importance for the better performance. Therefore, there have been researches to extract the gesture data from the touch data by means of machine learning algorithms. Xiao et al. [146] came up with an approach for estimating 3D finger angles such as pitch and yaw relative to a touchscreen's surface. It used the capacitive image that was the capacitance measured at each point of a touch sensor's capacitive grid. The pitch was estimated by a Gaussian process regression with 42 features and the yaw was computed by the major axis of the ellipsoid of the sensed touch pixels. While mean pitch errors were 9.7 and 14.5, mean yaw errors were 26.8 and 31.7 for phone and watch, respectively. It also proposed the possible applications such as zoom and rotate functions even with a single-touch event which would be very useful in small-size watch displays.

Mayer et al. [151] proposed the neural network approach to estimate the finger orientation of pitch and yaw. They evaluated the performance over separated deep neural networks (DNN) for pitch and yaw, combined DNN with two output neurons, and CNN along with L2 regularization [200,201] and batch normalization (BatchNorm) [202]. The blob detection provided the $15 \times 22$ sized data that was fed into neural networks. It achieved the best pitch error of 12.75 with $\mathrm{CNN}+\mathrm{L} 2+$ BatchNorm and the best yaw error of 17.6 with CNN.

Boceck et al. [161] extracted the pressure from capacitive images by using CNN. It used a ReLU function as an activation function, and dropout layers. Final fully connected layers contained LeakyReLU and L1/L2 regularization. They achieved the lower root mean square error of $471.99 \mathrm{~g}$, compared to $583.36 \mathrm{~g}$ and $593.51 \mathrm{~g}$ of RF and SVM.

Schweigert et al. [162] added knuckle related features by differentiating knuckles from fingers and classified 17 finger and knuckle gestures by CNN and long short-term memory (LSTM). CNN layers extracted the representation from the $15 \times 27$ capacitive image and then LSTM layers generated 17 outputs over 50 consecutive images through a softmax activation function. Seventeen gestures contained tap, two tap, swipe left, swipe right, swipe up, swipe down, two swipe up, two swipe down, circle, arrowhead left, arrowhead right, rotate, and five additional gestures. It achieved the accuracies of $97.9 \%$ and $86.8 \%$ on train and test sets, respectively.

\subsection{Accuracy Improvement}

Weir et al. [137] adopted GPR to find a mapping between two-dimensional reported touch locations and a corresponding intended two-dimensional touch location on the display. It collected the touch data by randomly displaying the crosshairs that the users had to touch. The resultant average reductions in error rates were $23.79 \%$ for $2 \mathrm{~mm}$ buttons, $14.79 \%$ for $3 \mathrm{~mm}$ buttons, and $5.11 \%$ for $4 \mathrm{~mm}$ buttons.

Fischer et al. [155] presented a system using capacitive sensing to accurately classify hand touches and proximity. Touch data were collected through 50 finger touches with different fingers, angles, locations and speeds, 25 glove touches, and 20 non-valid touches. Then, the collected data were further processed by dimensionality reduction, data augmentation, and normalization. Hidden Markov model (HMM) and RNN of gated recurrent 
units (GRUs) were evaluated as the classifier over three classes of non-touch, near, and touch. The RNN model showed the better overall accuracy of $97.1 \%$ even with gloves while HMM achieved the accuracy performance of $84.21 \%$.

Kumar et al. [158] improved the accuracy of touch locations by CNN. The dataset consisted of capacitive images at the dimension of $15 \times 27$ as well as the estimated touch positions represented by the centroid of the touch blob. The proposed CNN achieved an average error offset of 41.23 pixels based on a screen resolution of $1920 \times 1080$ on a 4.94 inch display. It was the improvement of $23.0 \%$, compared to the error offset of 50.7 pixels of the standard touch controller.

Kim et al. [160] introduced a sensor substitution system that generates time-series sensor data based on RNN. It estimated capacitive touch sensor signals by motion and audio signals caused by touch. By other types of multivariate time-series signals, the touch sensor sequences were supplemented even at dynamic and hostile environments that degraded the touch sensor's performance.

\subsection{Input Discrimination}

There have been studies on the discrimination of inputs such as fingers, palm, and stylus. Schwarz et al. [142] employed the decision tree to distinguish between legitimate stylus and palm based on spatiotemporal touch features and iterative classification. It identified five properties of palms such as the large contact area, the segmentation into a collection of touch points, the clustering, the area change, and the little movements. As a result, min distance to other touches, number of touch events, and $\mathrm{min} / \mathrm{mean} / \mathrm{max} / \mathrm{stdev}$ of touch radius were used as the features. The instant classification achieved an accuracy of $98.4 \%$ and the continuous iterative classification increased the accuracy to $99.5 \%$.

Le et al. [154] differentiated between touches of fingers and palm to devise an additional input modality. Their PalmTouch showed possible one-handed and two-handed palm interactions by placing flat hand or fist on the screen. It used the capacitive images for the features and CNN for the classification, leading to the accuracy of $99.53 \%$.

Le et al. [153] proposed the finger-aware interaction that identified fingers touching the whole device surface to add the input modalities. In a prototype, front and back side touchscreens were developed by two stacked smartphones and their three edges were attached with 37 capacitive sensors. It used CNN with L2 regularization to obtain 15 outputs that were a three-dimensional coordinate, $(x, y, z)$, for five fingers. The identification accuracy was $95.78 \%$ with the position error of $0.74 \mathrm{~cm}$.

Seol et al. $[157,163,203]$ employed the machine learning based classifiers such as SVM and autoencoder-based AD for finger and stylus discrimination. The higher frequency pulses were transmitted from a stylus to a capacitive touchscreen and the outputs of the charge amplifiers were sampled by ADC and classified by the classifier into no-touch, finger-touch, and stylus-touch. While no-touch and finger-touch were the constant level sample sequences, the stylus-touch was the random sequence between two constant levels. Therefore, SVM and AD classifiers achieved lower bit error rates (BERs) than $10^{-6}$ with the palm rejection. In addition, it was shown that its data communication algorithm could be applied in data transmission and user identification.

\section{Conclusions and Future Directions}

In this paper, we have provided an extensive review on touchscreen technologies. We mainly dealt with the overview of various touchscreen schemes from resistive to optical methods, and two main research directions of SNR improvement and stylus support as well as machine learning approaches in mutual capacitance capacitive touchscreens that are the most widely adopted scheme at present in smartphones, tablet PCs, notebook PCs, and smartwatches. For the aspect of the SNR improvement, accumulation, differential sensing, TMDS, dual mode of self and mutual capacitance, CDMS, delta-sigma modulation, and multiple-frequency driving have been introduced. High SNRs have been achieved by reduced noises and increased dynamic ranges. For the stylus support, passive, active, 
multiple frequency driving, ECR, and ML-based schemes have been addressed along with their pressure sensing capabilities. The machine learning applications in capacitive touchscreens have been classified in four categories of user identification/authentication, gesture detection, accuracy improvement, and input discrimination by means of a variety of algorithms such as DT, RF, NB, RBFN, BPNN, SVM, GPR, CNN, AD, and RNN.

Although many advancements have been accomplished in touchscreen technologies, challenges still exist in various fields. We will point out some of these challenges. We hope that this review not only helps the understanding of the touchscreen technologies but also paves the way to future researches on integrating machine learning algorithms into touchscreens for more various applications. As the resolutions of touchscreens are getting larger, fingerprints can be detected on any locations of the screen without additional sensors $[204,205]$. However, high power consumption and low scan rate should be addressed. One of possible solutions would be the super-resolution (SR) that gives rise to the high resolution capacitive image from the low resolution capacitive image. Many deep-learning-based SR algorithms have been reported [206,207]. As discussed in the previous sections, the SNR is one of the most important performance metrics and the high SNR is required to integrate touch sensing and display driving electronics into one integrated circuit. There exists the research field of de-noising that generates the clean one from the noisy image. Therefore, this de-noising scheme can be applied to enhance the SNR over the acquired capacitive images. Lastly, because latest smartphones, tablet PCs, and notebook PCs contain many sensors such as cameras, IR sensors, microphones, accelerometers, and gyroscopes besides touchscreens, there will keep being many approaches based on multi-sensor fusion technologies in the user interface field.

Author Contributions: Conceptualization, H.N. and K.-H.S.; formal analysis, H.N. and K.-H.S.; resources, H.N., K.-H.S., J.L., H.C., and S.W.J.; writing-original draft preparation, H.N.; writingreview and editing, H.N. and K.-H.S.; visualization, H.N.; supervision, H.N.; project administration, H.N.; funding acquisition, H.N. All authors have read and agreed to the published version of the manuscript.

Funding: This research was supported by IDEC (EDA Tool) and the National Research Foundation of Korea (NRF) funded by the Ministry of Science, ICT \& Future Planning (NRF-2016R1A2B4009787) and the Brain Korea 21 Four Program in 2021.

Institutional Review Board Statement: Not applicable.

Informed Consent Statement: Not applicable.

Data Availability Statement: Data sharing not applicable.

Conflicts of Interest: The authors declare no conflict of interest.

\section{References}

1. Cundall, C.M. Cathode-ray-tube display systems. Electron. Power 1968, 14, 115-120. [CrossRef]

2. Anderson, L.K. The Cathode Ray Tube Display: Why Use Anything Else? J. Vac. Sci. Technol. 1973, 10, 761. [CrossRef]

3. Seats, P. Fundamentals of Cathode-Ray Tubes. In Digest of Technical Papers of the International Symposium of the SID; Winner: New York, NY, USA, 1976; pp. 172-173.

4. Lehrer, N.H. Flat-Panel Displays and CRTs; Springer: Heidelberg, Germany, 1985.

5. Bitzer, D.L.; Slottow, H.G. The plasma display panel: A digitally addressable display with inherent memory. In Proceedings of the American Federation of Information Processing Societies (Fall), San Francisco, CA, USA, 7-10 November 1966; pp. 541-547.

6. Meunier, J.; Belenguer, P.; Boeuf, J.P. Numerical model of an ac plasma display panel cell in neon-xenon mixtures. J. Appl. Phys. 1995, 78, 731-745. [CrossRef]

7. Rauf, S.; Kushner, M.J. Dynamics of a coplanar-electrode plasma display panel cell. I. Basic operation. J. Appl. Phys. 1999, 85, 3460-3469. [CrossRef]

8. Rauf, S.; Kushner, M.J. Dynamics of a coplanar-electrode plasma display panel. II. Cell optimization. J. Appl. Phys. 1999, 85, 3470-3476. [CrossRef]

9. Shinoda, T.; Wakitani, M.; Nanto, T.; Awaji, N.; Kanagu, S. Development of panel structure for a high-resolution 21-in-diagonal full-color surface-discharge plasma display panel. IEEE Trans. Electron. Devices 2000, 47, 77-81. [CrossRef] 
10. Boeuf, J.P. Plasma display panels: Physics, recent developments and key issues. J. Phys. D Appl. Phys. 2003, 36, R53-R79. [CrossRef]

11. White, D.L.; Taylor, G.N. New absorptive mode reflective liquid-crystal display device. J. Appl. Phys. 1974, 45, 4718-4723. [CrossRef]

12. Snell, A.J.; Mackenzie, K.D.; Spear, W.E.; LeComber, P.G.; Hughes, A.J. Application of amorphous silicon field effect transistors in addressable liquid crystal display panels. Appl. Phys. 1981, 24, 357-362. [CrossRef]

13. Castellano, J.A. Liquid Crystal Display Applications: Past, Present \& Future. Liq. Cryst. Today 1991, 1, 4-6. [CrossRef]

14. Ishii, Y. The World of Liquid-Crystal Display TVs-Past, Present, and Future. J. Disp. Technol. 2007, 3, 351-360. [CrossRef]

15. Kim, D.H.; Lim, Y.J.; Kim, D.E.; Ren, H.; Ahn, S.H.; Lee, S.H. Past, present, and future of fringe-field switching-liquid crystal display. J. Inf. Disp. 2014, 15, 99-106. [CrossRef]

16. Tang, C.W.; VanSlyke, S.A. Organic electroluminescent diodes. Appl. Phys. Lett. 1987, 51, 913-915. [CrossRef]

17. Baldo, M.A.; O’Brien, D.F.; You, Y.; Shoustikov, A.; Sibley, S.; Thompson, M.E.; Forrest, S.R. Highly efficient phosphorescent emission from organic electroluminescent devices. Nature 1998, 395, 151-154. [CrossRef]

18. Adachi, C.; Baldo, M.A.; Thompson, M.E.; Forrest, S.R. Nearly 100\% internal phosphorescence efficiency in an organic lightemitting device. J. Appl. Phys. 2001, 90, 5048-5051. [CrossRef]

19. Arnold, A.D.; Castro, P.E.; Hatwar, T.K.; Hettel, M.V.; Kane, P.J.; Ludwicki, J.E.; Miller, M.E.; Murdoch, M.J.; Spindler, J.P.; Slyke, S.A.V.; Mameno, K.; Nishikawa, R.; Omura, T.; Matsumoto, S. Full-color AMOLED with RGBW pixel pattern. J. Soc. Inf. Disp. 2005, 13, 525-535. [CrossRef]

20. Nathan, A.; Chaji, G.; Ashtiani, S. Driving schemes for a-Si and LTPS AMOLED displays. J. Disp. Technol. 2005, 1, 267-277. [CrossRef]

21. Geffroy, B.; le Roy, P.; Prat, C. Organic light-emitting diode (OLED) technology: Materials, devices and display technologies. Polym. Int. 2006, 55, 572-582. [CrossRef]

22. Chen, H.W.; Lee, J.H.; Lin, B.Y.; Chen, S.; Wu, S.T. Liquid crystal display and organic light-emitting diode display: Present status and future perspectives. Light Sci. Appl. 2018, 7, 17168. [CrossRef]

23. Lee, V.W.; Twu, N.; Kymissis, I. Micro-LED Technologies and Applications. Inf. Disp. 2016, 32, 16-23. [CrossRef]

24. Wu, T.; Sher, C.W.; Lin, Y.; Lee, C.F.; Liang, S.; Lu, Y.; Chen, S.W.H.; Guo, W.; Kuo, H.C.; Chen, Z. Mini-LED and Micro-LED: Promising Candidates for the Next Generation Display Technology. Appl. Sci. 2018, 8, 1557. [CrossRef]

25. Paranjpe, A.; Montgomery, J.; Lee, S.M.; Morath, C. Micro-LED Displays: Key Manufacturing Challenges and Solutions. Dig. Tech. Pap. Int. Symp. SID 2018, 49, 597-600. [CrossRef]

26. Huang, Y.; Tan, G.; Gou, F.; Li, M.; Lee, S.; Wu, S. Prospects and challenges of mini-LED and micro-LED displays. J. Soc. Inf. Disp. 2019, 27, 387-401. [CrossRef]

27. Zhoua, X.; Tiana, P.; Sher, C.W.; Wu, J.; Liu, H.; Liu, R.; Kuo, H.C. Growth, transfer printing and colour conversion techniques towards full-colour micro-LED display. Prog. Quantum. Electron. 2020, 71, 100263. [CrossRef]

28. Huang, Y.; Hsiang, E.L.; Deng, M.Y.; Wu, S.T. Mini-LED, Micro-LED and OLED displays: Present status and future perspectives. Light Sci. Appl. 2020, 9, 105. [CrossRef] [PubMed]

29. Schaeffler, J. Digital Signage: Software, Networks, Advertising, and Displays: A Primer for Understanding the Business; Taylor \& Francis: Oxfordshire, UK, 2008.

30. Nam, H.; Lee, S.W. Low-power liquid crystal display television panel with reduced motion blur. IEEE Trans. Consum. Electron. 2010, 56, 307-311. [CrossRef]

31. Nam, H. Low power active dimming liquid crystal display with high resolution backlight. Electron. Lett. 2011, 47, 538-540. [CrossRef]

32. Han, S.M.; Lee, B.W.; Ji, I.H.; Sung, S.D.; Arkhipov, A.; Kim, S.S. Smart Power-Saving Driving Scheme for AMOLEDs Using Dynamic Power Rail Control. Dig. Tech. Pap. Int. Symp. SID 2011, 42, 183-185. [CrossRef]

33. You, B.H.; Bae, J.S.; Park, D.W.; Hong, S.H.; Saito, S.; Moon, J.T. UD Resolution 240Hz LCD TV Display System with High Speed Driving. Dig. Tech. Pap. Int. Symp. SID 2012, 43, 395-398. [CrossRef]

34. de Greef, P.; Hulzeu, H.G. Adaptive Dimming and Boosting Backlight for LCD-TV Systems. Dig. Tech. Pap. Int. Symp. SID 2012, 38, 1332-1335. [CrossRef]

35. Nam, W.; Shim, J.; Shin, H.; Kim, J.; Ha, W.; Park, K.; Kim, H.; Kim, B.; Oh, C.; Ahn, B.; et al. 55-inch OLED TV using InGaZnO TFTs with WRGB Pixel Design. Dig. Tech. Pap. Int. Symp. SID 2013, 44, 243-246. [CrossRef]

36. Hara, Y.; Kikuchi, T.; Kitagawa, H.; Morinaga, J.; Ohgami, H.; Imai, H.; Daitoh, T.; Matsuo, T. IGZO-TFT technology for large-screen 8K display. J. Soc. Inf. Disp. 2018, 26, 169-177. [CrossRef]

37. Shin, H.J.; Takasugi, S.; Choi, W.S.; Chang, M.K.; Choi, J.Y.; Jeon, S.K.; Yun, S.H.; Park, H.W.; Kim, J.M.; Kim, H.S.; et al. A Novel OLED Display Panel with High-Reliability Integrated Gate Driver Circuit using IGZO TFTs for Large-Sized UHD TVs. Dig. Tech. Pap. Int. Symp. SID 2018, 49, 358-361. [CrossRef]

38. Shin, H.J.; Choi, W.S.; Chang, M.K.; Choi, J.Y.; Choi, S.H.; Yun, S.H.; Kim, J.M.; Kim, H.S.; Oha, C.H. A High Image-Quality OLED Display with Integrated Gate Driver using MPRT Enhancement Technology for Large Size Premium TVs. Dig. Tech. Pap. Int. Symp. SID 2019, 50, 199-202. [CrossRef]

39. Bae, K.S.; Oh, M.; Park, B.; Cho, Y.J.; Cho, S.H.; Kim, D. Novel Pixel Structure for 8K QUHD LCD Panel with the Enhanced Optical Performances. Dig. Tech. Pap. Int. Symp. SID 2019, 50, 703-706. [CrossRef] 
40. Consumer Reports, TV Trends to Watch in 2021. Available online: https://www.consumerreports.org/lcd-led-oled-tvs/tvtrends-to-watch-for/ (accessed on 17 April 2021).

41. PC Magazine, The Best TVs for 2021. Available online: https://www.pcmag.com/picks/the-best-tvs (accessed on 17 April 2021).

42. CNet, CES 2018 Wrap-Up: The TVs of Tomorrow Will Turn Invisible. Available online: https://www.cnet.com/news / ces-2018 -wrap-up-the-tvs-of-tomorrow-will-turn-invisible/ (accessed on 17 April 2021).

43. Kim, S.; Kwon, H.; Lee, S.; Shim, H.; Chun, Y.; Choi, W.; Kwack, J.; Han, D.; Song, M.; Kim, S.; et al. Low-Power Flexible Organic Light-Emitting Diode Display Device. Adv. Mater. 2011, 23, 3511-3516. [CrossRef]

44. Takubo, Y.; Hisatake, Y.; Lizuka, T.; Kawamura, T. Ultra-High Resolution Mobile Displays. Dig. Tech. Pap. Int. Symp. SID 2012, 43, 869-872. [CrossRef]

45. Sakaigawa, A.; Kabe, M.; Harada, T.; Goto, F.; Takasaki, N.; Mitsui, M.; Nakahara, T.; Ikeda, K.; Seki, K.; Nagatsuma, T.; et al. Low Power Consumption Technology for Ultra-High Resolution Mobile Display by Using RGBW System. IEICE Trans. Electron. 2013, E96-C, 1367-1372. [CrossRef]

46. Ohshima, H. Mobile display technologies: Past developments, present technologies, and future opportunities. Jpn. J. Appl. Phys. 2014, 53. [CrossRef]

47. Yan, J.; Ho, J.; Chen, J. Foldable AMOLED Display Development: Progress and Challenges. Inf. Disp. 2015, 31, 12-16. [CrossRef]

48. Kim, J.S.; Lee, S.W. Peripheral Dimming: A New Low-Power Technology for OLED Display Based on Gaze Tracking. IEEE Access 2020, 8, 209064-209073. [CrossRef]

49. Tom's Guide, Best Big Phones of 2021: Top Phablets 6 Inches or Larger. Available online: https: / / www.tomsguide.com/bestpicks/best-big-phones (accessed on 17 April 2021).

50. Bastani, B.; Turner, E.; Vieri, C.; Jiang, H.; Funt, B.; Balram, N. Foveated Pipeline for AR/VR Head-Mounted Displays. Inf. Disp. 2017, 33, 14-35. [CrossRef]

51. Bhowmik, A.K. Advances in Virtual, Augmented, and Mixed Reality Technologies. Inf. Disp. 2018, 34, 18-21. [CrossRef]

52. Vieri, C.; Lee, G.; Balram, N.; Jung, S.H.; Yang, J.Y.; Yoon, S.Y.; Kang, I.B. An 18 megapixel $4.3^{\prime \prime} 1443$ ppi 120 Hz OLED display for wide field of view high acuity head mounted displays. J. Soc. Inf. Disp. 2018, 26, 314-324. [CrossRef]

53. Park, S.; Kim, Y.I.; Nam, H. Foveation-based reduced resolution driving scheme for immersive virtual reality displays. Opt. Express 2019, 27, 29594-29605. [CrossRef]

54. Muñoz-Saavedra, L.; Miró-Amarante, L.; Domínguez-Morales, M. Augmented and Virtual Reality Evolution and Future Tendency. Appl. Sci. 2020, 10, 322. [CrossRef]

55. Zhan, T.; Yin, K.; Xiong, J.; He, Z.; Wu, S.T. Augmented Reality and Virtual Reality Displays: Perspectives and Challenges. iScience 2020, 23, 101397. [CrossRef]

56. Lee, B.; Yoo, C.; Jeong, J.; Lee, B.; Bang, K. Key issues and technologies for AR/VR head-mounted displays. In Proceedings of the SPIE 11304, Advances in Display Technologies X, San Francisco, CA, USA, 1-6 February 2020; p. 1130402.

57. Jang, H.J.; Lee, J.Y.; Kim, J.; Kwak, J.; Park, J.H. Progress of display performances: AR, VR, QLED, and OLED. J. Inf. Disp. 2020, 21, 1-9. [CrossRef]

58. Kim, H.; Kwak, B.C.; Lim, H.S.; Kwon, O.K. Pixel Circuit for Organic Light-Emitting Diode-on Silicon Microdisplays Using the Source Follower Structure. Jpn. J. Appl. Phys. 2010, 49, 03CD05. [CrossRef]

59. Kwak, B.C.; Lim, H.S.; Kwon, O.K. Organic Light-Emitting Diode-on-Silicon Pixel Circuit Using the Source Follower Structure with Active Load for Microdisplays. Jpn. J. Appl. Phys. 2011, 50, 03CC05. [CrossRef]

60. Hong, S.W.; Kwak, B.C.; Na, J.S.; Hong, S.K.; Kwon, O.K. Simple pixel circuits for high resolution and high image quality organic light emitting diode-on-silicon microdisplays with wide data voltage range. J. Soc. Inf. Disp. 2016, 24, 110-116. [CrossRef]

61. Liu, B.; Ding, D.; Zhou, T.; Zhang, M. A Novel Pixel Circuit Providing Expanded Input Voltage Range for OLEDoS Microdisplays. Dig. Tech. Pap. Int. Symp. SID 2017, 48, 1438-1441. [CrossRef]

62. Huo, X.; Liao, C.; Wu, J.; Yi, S.; Wang, Y.; Jiao, H.; Zhang, M.; Zhang, S. An OLEDoS Pixel Circuit with Extended Data Voltage Range for High Resolution Micro-Displays. Dig. Tech. Pap. Int. Symp. SID 2018, 49, 1373-1376. [CrossRef]

63. Na, J.S.; Hong, S.K.; Kwon, O.K. A 4410-ppi Resolution Pixel Circuit for High Luminance Uniformity of OLEDoS Microdisplays. IEEE J. Electron Devices Soc. 2019, 7, 1026-1032. [CrossRef]

64. Wadlow, T.A. The Xerox Alto Computer. Byte Mag. 1981, 6, 58-68.

65. Knight, L.W.; Retter, D. Datahand: Design, Potential Performance, and Improvements in the Computer Keyboard and Mouses. Proc. Hum. Factors Soc. Annu. Meet. 1989, 33, 450-454. [CrossRef]

66. Wolf, C.G. A comparative study of gestural, keyboard, and mouse interfaces. Behav. Inf. Technol. 1992, 11, 13-23. [CrossRef]

67. Mahach, K.R. A Comparison of Computer Input Devices: Linus Pen, Mouse, Cursor Keys and Keyboard. Proc. Hum. Factors Soc. Annu. Meet. 1989, 33, 330-334. [CrossRef]

68. Colla, R.; Ziab, K.; Collc, J.H. A comparison of three computer cursor control devices: Pen on horizontal tablet, mouse and keyboard. Inf. Manag. 1994, 27, 329-339. [CrossRef]

69. Sharples, M.; Beale, R. A technical review of mobile computational devices. J. Comput. Assist. Learn. 2003, 19, 392-395. [CrossRef]

70. Walker, G. Tablet Product and Market History. Available online: http://walkermobile.com/Tablet_History.pdf (accessed on 17 April 2021).

71. Lin, C.H.; Schmidt, K.J. User Preference and Performance with Three Different Input Devices: Keyboard, Mouse, or Touchscreen. Educ. Technol. 1993, 33, 56-59. 
72. Bakhtiyari, K.; Taghavi, M.; Husain, H. Hybrid affective computing-Keyboard, mouse and touch screen: From review to experiment. Neural Comput. Appl. 2015, 26, 1277-1296. [CrossRef]

73. Walker, G. Touch Displays. In Handbook of Digital Imaging; Kriss, M., Ed.; John Wiley \& Sons, Ltd.: Hoboken, NJ, USA, 2015.

74. Noah, B.; Li, J.; Rothrock, L. An evaluation of touchscreen versus keyboard/mouse interaction for large screen process control displays. Appl. Ergon. 2017, 60,1-13. [CrossRef]

75. Vaughan, N.; Steven, J. New Interfaces at the Touch of a Fingertip. Computer 2007, 40, 12-15. [CrossRef]

76. Bhalla, M.R.; Bhalla, A.V. Comparative Study of Various Touchscreen Technologies. Int. J. Comput. Appl. 2010, 6, 12-18. [CrossRef]

77. Colegrove, J. The State of the Touch-Screen Market in 2010. Inf. Disp. 2010, 26, 22-24. [CrossRef]

78. Aguilar, R.N.; Meijer, G.C.M. Fast interface electronics for a resistive touch-screen. In Proceedings of the IEEE Sensors, Orlando, FL, USA, 12-14 June 2002.

79. Downs, R. Texas Instruments Inc., Using Resistive Touch Screens for Human/Machine Interface. Available online: https: / /www.ti.com/jp/lit/an/slyt209a/slyt209a.pdf (accessed on 23 April 2021).

80. Stetson, J.W. Analog Resistive Touch Panels and Sunlight Readability. Inf. Disp. 2006, 12, $26-30$.

81. Krein, P.T.; Meadows, R.D. The electroquasistatics of the capacitive touch panel. IEEE Trans. Ind. Appl. 1990, 26, 529-534. [CrossRef]

82. Barrett, G.; Omote, R. Projected-Capacitive Touch Technology. Inf. Disp. 2010, 26, 16-21. [CrossRef]

83. Yanase, J.; Takatori, K.; Asada, H. Algorithm for Recognizing Pinch Gestures on Surface-Capacitive Touch Screens. Dig. Tech. Pap. Int. Symp. SID 2015, 46, 899-902. [CrossRef]

84. Walker, G. Part 1: Fundamentals of Projected-Capacitive Touch Technology. Available online: http://www.walkermobile.com/ Touch_Technologies_Tutorial_Latest_Version.pdf (accessed on 23 April 2021).

85. Dieulesaint, E.; Royer, D.; Legras, O.; Chaabi, A. Acoustic plate mode touch screen. Electron. Lett. 1991, 27, 49-51. [CrossRef]

86. Nara, T.; Takasaki, M.; Maeda, T.; Higuchi, T.; Ando, S.; Tachi, S. Surface acoustic wave tactile display. IEEE Comput. Graph. Appl. 2001, 21, 56-63. [CrossRef]

87. Takasaki, M.; Kotani, H.; Mizuno, T.; Nara, T. Transparent surface acoustic wave tactile display. In Proceedings of the IEEE/RSJ International Conference on Intelligent Robots and Systems, Edmonton, AB, Canada, 2-6 August 2005; pp. $3354-3359$.

88. North, K.; D'Souza, H. Acoustic Pulse Recognition Enters Touch-Screen Market. Inf. Disp. 2006, 12, $22-25$.

89. Harris, N. Applications of Bending Wave Technology in Human Interface Devices. J. Audio Eng. Soc. $2009 ; 7658$.

90. Reis, S.; Correia, V.; Martins, M.; Barbosa, G.; Sousa, R.M.; Minas, G.; Lanceros-Mendez, S.; Rocha, J.G. Touchscreen based on acoustic pulse recognition with piezoelectric polymer sensors. In Proceedings of the IEEE International Symposium on Industrial Electronics, Bari, Italy, 4-7 July 2010; pp. 516-520.

91. Hao, X.; Huang, K. A Low-Power Ultra-Light Small and Medium Size Acoustic Wave Touch Screen. Appl. Mech. Mater. 2014, 513-517, 4072-4075. [CrossRef]

92. Quaegebeur, N.; Masson, P.; Beaudet, N.; Sarret, P. Touchscreen Surface Based on Interaction of Ultrasonic Guided Waves with a Contact Impedance. IEEE Sens. J. 2016, 16, 3564-3571. [CrossRef]

93. Firouzi, K.; Nikoozadeh, A.; Carver, T.E.; Khuri-Yakub, B.T. Multitouch touchscreen using reverberant lamb waves. In Proceedings of the IEEE International Ultrasonics Symposium, Washington, DC, USA, 6-9 September 2017; pp. 1-4.

94. Yang, Z.; Liu, X.; Wu, B.; Liu, R. Adaptability of Ultrasonic Lamb Wave Touchscreen to the Variations in Touch Force and Touch Area. Sensors 2021, 21, 1736. [CrossRef]

95. Han, J.Y. Low-cost multi-touch sensing through frustrated total internal reflection. In Proceedings of the 18th annual ACM symposium on User interface software and technology, Seattle, WA, USA, 23-26 October 2005; pp. 115-118.

96. Maxwell, I. An Overview of Optical-Touch Technologies. Inf. Disp. 2007, 12, 26-30.

97. Zhang, H. Optical touch screen with virtual force. In Proceedings of the IEEE International Conference on Systems, Man and Cybernetics, San Antonio, TX, USA, 11-14 October 2009; pp. 807-811.

98. Sheikh, S.S.A.; Hanana, S.M.; Al-Hosany, Y.; Soudan, B. Design and implementation of an FTIR camera-based multi-touch display. In Proceedings of the 5th IEEE GCC Conference \& Exhibition, Kuwait, Kuwait, 17-19 March 2009, pp. 1-6.

99. Ahsanullah.; Mahmood, A.K.B.; Sulaiman, S. Design and implementation of multi-touch system using FTIR technique for optimization of finger touch detection. In Proceedings of the International Symposium on Information Technology, Kuala Lumpur, Malaysia, 15-17 June 2010; Volume 1, pp. 1-7.

100. Pedersen, H.C.; Jakobsen, M.L.; Hanson, S.G.; Mosgaard, M.; Iversen, T.; Korsgaard, J. Optical touch screen based on waveguide sensing. Appl. Phys. Lett. 2011, 99, 061102. [CrossRef]

101. Han, J.; Choi, S.; Heo, S.; Lee, G. Optical touch sensing based on internal scattering in touch surface. Electron. Lett. 2012, 48, 1420-1422. [CrossRef]

102. Park, S.M.; Lee, K.; Kyung, K.U. A new stylus for touchscreen devices. In Proceedings of the IEEE International Conference on Consumer Electronics, Las Vegas, NV, USA, 9-12 January 2011, pp. 491-492.

103. Badaye, M.; Schediwy, R.R. Passive Stylus for Capacitive Sensors. U.S. Patent 8,125,469 B2, 28 February 2012.

104. Zachut, R. Digitizer, Stylus and Method of Synchronization Therewith. U.S. Patent 9,524,044 B2, 20 December 2016.

105. Vuppu, S.; Cranfill, D.; Olley, M.; Valentine, M. Active Stylus for Use with Touch-Sensitive Interfaces and Corresponding Method. U.S. Patent 8,766,954 B2, 1 July 2014.

106. Shahparnia, S.; Sundara-Rajan, K.; Ali, Y.; Bentov, I. Active Stylus with High Voltage. U.S. Patent 9,933,866 B2, 3 April 2018. 
107. Chen, C.H.; Huang, C.H. Method for Sensing Fast Motion, Controller and Electromagnetic Sensing Apparatus. U.S. Patent 2015/0331504 A1, 19 November 2015.

108. An, J.S.; Han, S.H.; Kim, J.E.; Yoon, D.H.; Kim, Y.H.; Hong, H.H.; Ye, J.H.; Jung, S.J.; Lee, S.H.; Jeong, J.Y.; et al. 9.6 A 3.9 kHzframe-rate capacitive touch system with pressure/tilt angle expressions of active stylus using multiple-frequency driving method for 65" $104 \times 64$ touch screen panel. In Proceedings of the IEEE International Solid-State Circuits Conference, San Francisco, CA, USA, 5-9 February 2017, pp. 168-169.

109. Park, S.M.; Lee, K.; Kyung, K.U. Target size study for one-handed thumb use on small touchscreen devices. In Proceedings of the Conference on Human-Computer Interaction with Mobile Devices and Services, Helsinki, Finland, 12-15 September 2006; pp. 203-210.

110. Butler, A.; Izadi, S.; Hodges, S. SideSight: Multi-"touch" interaction around small devices. In Proceedings of the Annual ACM Symposium on User Interface Software and Technology, Monterey, CA, USA, 19-22 October 2008; pp. 201-204.

111. Harrison, C.; Hudson, S.E. Abracadabra: Wireless, high-precision, and unpowered finger input for very small mobile devices. In Proceedings of the Annual ACM Symposium on User Interface Software and Technology, Victoria, BC, Canada, 4-7 October 2009; pp. 121-124.

112. Dybdal, M.L.; Agustin, J.S.; Hansen, J.P. Gaze input for mobile devices by dwell and gestures. In Proceedings of the Symposium on Eye Tracking Research and Applications, Santa Barbara, CA, USA, 28-30 March 2012; pp. 225-228.

113. Stellmach, S.; Dachselt, R. Look \& touch: Gaze-supported target acquisition. In Proceedings of the SIGCHI Conference on Human Factors in Computing Systems, Austin, TX, USA, 5-10 May 2008; pp. 2981-2990.

114. Xiao, R.; Laput, G.; Harrison, C. Expanding the input expressivity of smartwatches with mechanical pan, twist, tilt and click. In Proceedings of the SIGCHI Conference on Human Factors in Computing Systems, Toronto, ON, Canada, 26 April-1 May 2014; pp. 193-196.

115. Oakley, I.; Lee, D. Interaction on the edge: Offset sensing for small devices. In Proceedings of the SIGCHI Conference on Human Factors in Computing Systems, Toronto, ON, Canada, 26 April-1 May 2014; pp. 169-178.

116. Lim, S.C.; Shin, J.; Kim, S.C.; Park, J. Expansion of Smartwatch Touch Interface from Touchscreen to Around Device Interface Using Infrared Line Image Sensors. Sensors 2015, 15, 16642-16653. [CrossRef]

117. Zhou, J.; Zhang, Y.; Laput, G.; Harrison, C. AuraSense: Enabling Expressive Around-Smartwatch Interactions with Electric Field Sensing. In Proceedings of the Annual Symposium on User Interface Software and Technology, Tokyo, Japan, 16-19 October 2016; pp. $81-86$.

118. Zhang, C.; Guo, A.; Zhang, D.; Li, Y.; Southern, C.; Arriaga, R.I.; Abowd, G.D. Beyond the Touchscreen: An Exploration of Extending Interactions on Commodity Smartphones. ACM Trans. Interact. Intell. Syst. 2016, 6, 16. [CrossRef]

119. Weigel, M.; Steimle, J. DeformWear: Deformation Input on Tiny Wearable Devices. Proc. ACM Interact. Mobile Wearable Ubiquitous Technol. $2017,1,1-23$. [CrossRef]

120. Lee, J.; Lee, C.; Kim, G.J. Vouch: Multimodal touch-and-voice input for smart watches under difficult operating conditions. J. Multimodal User Interfaces 2017, 11, 289-299. [CrossRef]

121. Kwon, M.C.; Park, G.; Choi, S. Smartwatch User Interface Implementation Using CNN-Based Gesture Pattern Recognition. Sensors 2018, 18, 2997. [CrossRef]

122. Song, S.J.; Nam, H. Sound-of-Tapping user interface technology with medium identification. Displays 2018, 53, 54-64. [CrossRef]

123. Wang, B.; Grossman, T. BlyncSync: Enabling Multimodal Smartwatch Gestures with Synchronous Touch and Blink. In Proceedings of the CHI Conference on Human Factors in Computing Systems, Honolulu, HI, USA, 25-30 April 2020; pp. 1-14.

124. Harrison, C.; Schwarz, J.; Hudson, S.E. TapSense: enhancing finger interaction on touch surfaces. In Proceedings of the Annual ACM Symposium on User Interface Software and Technology, Barbara, CA, USA, 16-19 October 2011; pp. 627-636.

125. Ikematsu, K.; Yamanaka, S. ScraTouch: Extending Touch Interaction Technique Using Fingernail on Capacitive Touch Surfaces. In Proceedings of the Extended Abstracts of the CHI Conference on Human Factors in Computing Systems, Honolulu, HI, USA, 25-30 April 2020, pp. 1-10.

126. Ha, T.; Woo, W. Bare Hand Interface for Interaction in the Video See-Through HMD Based Wearable AR Environment. In Proceedings of the International Conference on Entertainment Computing, Cambridge, UK, 20-22 September 2006.

127. Witt, H.; Nicolai, T.; Kenn, H. Designing a wearable user interface for hands-free interaction in maintenance applications. In Proceedings of the Annual IEEE International Conference on Pervasive Computing and Communications Workshops, Pisa, Italy, 13-17 March 2006.

128. Lee, S.; Ha, G.; Cha, J.; Kim, J.; Lee, H.; Kim, S. CyberTouch-Touch and Cursor Interface for VR HMD. In Proceedings of the Posters' Extended Abstracts of International Conference on Human-Computer Interaction, Los Angeles, CA, USA, 2-7 August 2015.

129. Sidorakis, N.; Koulieris, G.A.; Mania, K. Binocular eye-tracking for the control of a 3D immersive multimedia user interface. In Proceedings of the IEEE Workshop on Everyday Virtual Reality, Arles, France, 23 March 2015; pp. 15-18.

130. Ono, M.; Shizuki, B.; Tanaka, J. Sensing Touch Force using Active Acoustic Sensing. In Proceedings of the International Conference on Tangible, Embedded, and Embodied Interaction, Stanford, CA, USA, 15-19 January 2015; pp. 355-358.

131. Kim, J.; Cha, J.; Lee, H.; Kim, S. Hand-free natural user interface for VR HMD with IR based facial gesture tracking sensor. In Proceedings of the ACM Symposium on Virtual Reality Software and Technology, Gothenburg, Sweden, 8-10 November 2017; pp. 1-2. 
132. Kim, M.; Lee, J.; Jeon, C.; Kim, J. A Study on Interaction of Gaze Pointer-Based User Interface in Mobile Virtual Reality Environment. Symmetry 2017, 9, 189. [CrossRef]

133. Park, K.; Chin, S. Let us guide a smart interface for VR HMD and leap motion. In Proceedings of the ACM Symposium on Virtual Reality Software and Technology, Tokyo, Japan, 28 November-1 December 2018; pp. 1-2.

134. Hansen, J.P.; Alapetite, A.; Thomsen, M.; Wang, Z.; Minakata, K.; Zhang, G. Head and gaze control of a telepresence robot with an HMD. In Proceedings of the ACM Symposium on Eye Tracking Research \& Applications, Warsaw, Poland, 14-17 June 2018; pp. 1-3.

135. Kolly, S.M.; Wattenhofer, R.; Welten, S. A personal touch: Recognizing users based on touch screen behavior. In Proceedings of the International Workshop on Sensing Applications on Mobile Phones, Toronto, ON, Canada, 6 November 2012; pp. 1-5.

136. Angulo, J.; Wästlund, E. Exploring Touch-Screen Biometrics for User Identification on Smart Phones. IFIP Adv. Inf. Commun. Technol. 2012, 375, 130-143. [CrossRef]

137. Weir, D.; Rogers, S.; Murray-Smith, R.; Löchtefeld, M. A user-specific machine learning approach for improving touch accuracy on mobile devices. In Proceedings of the Annual ACM Symposium on User Interface Software and Technology, Cambridge, MA, USA, 7-10 October 2012; pp. 465-476.

138. Feng, T.; Liu, Z.; Kwon, K.A.; Shi, W.; Carbunar, B.; Jiang, Y.; Nguyen, N. Continuous mobile authentication using touchscreen gestures. In Proceedings of the IEEE Conference on Technologies for Homeland Security, Waltham, MA, USA, 13-15 November 2012.

139. Meng, Y.; Wong, D.; Schlegel, R.; Kwok, L. Touch Gestures Based Biometric Authentication Scheme for Touchscreen Mobile Phones. In Proceedings of the Lecture Notes in Computer Science of International Conference on Information Security and Cryptology, Guangzhou, China, 27-30 November 2013; pp. 110-113.

140. Saravanan, P.; Clarke, S.; Chau, D.H.P.; Zha, H. LatentGesture: Active user authentication through background touch analysis. In Proceedings of the International Symposium of Chinese CHI, Toronto, ON, Canada, 26-27 April 2014; pp. 110-113.

141. Meng, Y.; Wong, D.S.; Kwok, L.F. Design of touch dynamics based user authentication with an adaptive mechanism on mobile phones. In Proceedings of the Annual ACM Symposium on Applied Computing, Gyeongju, Korea, 24-28 March 2014; pp. 1680-1687.

142. Schwarz, J.; Xiao, R.; Mankoff, J.; Hudson, S.E.; Harrison, C. Probabilistic palm rejection using spatiotemporal touch features and iterative classification. In Proceedings of the SIGCHI Conference on Human Factors in Computing Systems, Toronto, ON, Canada, 26 April-1 May 2014.

143. Guo, A.; Xiao, R.; Harrison, C. CapAuth: Identifying and Differentiating User Handprints on Commodity Capacitive Touchscreens. In Proceedings of the International Conference on Interactive Tabletops \& Surfaces, Madeira, Portugal, 15-18 November 2015; pp. 59-62.

144. Lin, J.W.; Wang, C.; Huang, Y.Y.; Chou, K.T.; Chen, H.Y.; Tseng, W.L.; Chen, M.Y. BackHand: Sensing Hand Gestures via Back of the Hand. In Proceedings of the Annual ACM Symposium on User Interface Software \& Technology, Charlotte, NC, USA, 11-15 November 2015; pp. 557-564.

145. Buschek, D.; Alt, F. TouchML: A Machine Learning Toolkit for Modelling Spatial Touch Targeting Behaviour. In Proceedings of the International Conference on Intelligent User Interfaces, Atlanta, GA, USA, 29 March-1 April 2015; pp. 110-114.

146. Xiao, R.; Schwarz, J.; Harrison, C. Estimating 3d finger angle on commodity touchscreens. In Proceedings of the International Conference on Interactive Tabletops \& Surfaces, Madeira, Portugal, 15-18 November 2015.

147. Mock, P.; Gerjets, P.; Tibus, M.; Trautwein, U.; Möller, K.; Rosenstiel, W. Using touchscreen interaction data to predict cognitive workload. In Proceedings of the ACM International Conference on Multimodal Interaction, Tokyo, Japan, 12-16 November 2016.

148. Rilvan, M.A.; Lacy, K.I.; Hossain, M.S.; Wang, B. User authentication and identification on smartphones by incorporating capacitive touchscreen. In Proceedings of the IEEE International Performance Computing and Communications Conference, Las Vegas, NV, USA, 9-11 December 2016.

149. Sharma, V.; Enbody, R. User authentication and identification from user interface interactions on touch-enabled devices. In Proceedings of the ACM Conference on Security and Privacy in Wireless and Mobile Networks, Boston, MA, USA, 18-20 July 2017; pp. 1-11.

150. Henze, N.; Mayer, S.; Le, H.V.; Schwind, V. Improving software-reduced touchscreen latency. In Proceedings of the International Conference on Human-Computer Interaction with Mobile Devices and Services, Vienna, Austria, 4-7 September 2017; pp. 1-8.

151. Mayer, S.; Le, H.V.; Henze, N. Estimating the finger orientation on capacitive touchscreens using convolutional neural networks. In Proceedings of the ACM International Conference on Interactive Surfaces and Spaces, Brighton, UK, 17-20 October 2017.

152. Meng, W.; Li, W.; Wong, D.S. Enhancing touch behavioral authentication via cost-based intelligent mechanism on smartphones. Multimed. Tools Appl. 2018, 77, 30167-30185. [CrossRef]

153. Le, H.V.; Mayer, S.; Henze, N. InfiniTouch: Finger-Aware Interaction on Fully Touch Sensitive. In Proceedings of the Annual ACM Symposium on User Interface Software and Technology, Berlin, Germany, 14 October 2018; pp. 779-792.

154. Le, H.V.; Kosch, T.; Mayer, S.; Henze, N. Demonstrating palm touch: the palm as an additional input modality on commodity smartphones. In Proceedings of the International Conference on Human-Computer Interaction with Mobile Devices and Services Adjunct, Barcelona, Spain, 3-6 September 2018.

155. Fischer, T.; Etchart, M.; Biempica, E. Frame-level proximity and touch recognition using capacitive sensing and semi-supervised sequential modeling. In Proceedings of the IEEE International Workshop on Machine Learning for Signal Processing, Aalborg, Denmark, 17-20 September 2018. 
156. Le, H.V.; Kosch, T.; Bader, P.; Mayer, S.; Henze, N. PalmTouch: Using the Palm as an Additional Input Modality on Commodity Smartphones. In Proceedings of the CHI Conference on Human Factors in Computing Systems, Montreal, QC, Canada, 21-26 April 2018.

157. Seol, K.H.; Park, S.; Song, S.J.; Nam, H. Finger and stylus discrimination scheme based on capacitive touch screen panel and support vector machine classifier. Jpn. J. Appl. Phys. 2019, 58, 074501. [CrossRef]

158. Kumar, A.; Radjesh, A.; Mayer, S.; Le, H.V. Improving the Input Accuracy of Touchscreens using Deep Learning. In Proceedings of the Extended Abstracts of the CHI Conference on Human Factors in Computing Systems, Glasgow Scotland, UK, 4-9 May 2019.

159. Le, H.V.; Mayer, S.; Henze, N. Investigating the feasibility of finger identification on capacitive touchscreens using deep learning. In Proceedings of the International Conference on Intelligent User Interfaces, Marina del Ray, CA, USA, 17-20 March 2019.

160. Kim, S.C.; Han, B.K. Emulating touch signals from multivariate sensor data using gated RNNs. In Proceedings of the ACM/IEEE International Conference on Human-Robot Interaction, Marina del Ray, CA, USA, 17-20 March 2019.

161. Boceck, T.; Sprott, S.; Le, H.V.; Mayer, S. Force Touch Detection on Capacitive Sensors using Deep Neural Networks. In Proceedings of the International Conference on Human-Computer Interaction with Mobile Devices and Services, Taipei, Taiwan, 1-4 October 2019.

162. Schweigert, R.; Leusmann, J.; Hagenmayer, S.; Weiß, M.; Le, H.V.; Mayer, S.; Bulling, A. KnuckleTouch: Enabling Knuckle Gestures on Capacitive Touchscreens using Deep Learning. In Proceedings of the Mensch und Computer, Hamburg, Germany, 8-11 September 2019; pp. 387-397.

163. Seol, K.H.; Park, S.; Lee, J.; Nam, H. Active stylus-touch discrimination scheme based on anomaly detection algorithm. J. Soc. Inf. Disp. 2020, 28, 831-836. [CrossRef]

164. Bello, A.A.; Chiroma, H.; Gital, A.Y.; Gabralla, L.A.; Abdulhamid, S.M.; Shuib, L. Machine learning algorithms for improving security on touch screen devices: a survey, challenges and new perspectives. Neural Comput. Appl. 2020, 32, 13651-13678. [CrossRef]

165. Walker, G. A review of technologies for sensing contact location on the surface of a display. J. Soc. Inf. Disp. 2012, 20, 413-440. [CrossRef]

166. Kwon, O.K.; An, J.S.; Hong, S.K. Capacitive Touch Systems With Styli for Touch Sensors: A Review. IEEE Sens. J. 2018, 18, 4832-4846. [CrossRef]

167. Hansson, P.R. Multiple input detection for resistive touch panel. WO Patent 2009/156803 A1, 30 December 2009.

168. Bogana, M.P.; Celani, A.; Pastore, N. Method for Determining Multiple Touch Inputs on a Resistive Touch Screen and a Multiple Touch Controller. U.S. Patent 2012/0068969 A1, 22 March 2012.

169. Calpe-Maravilla, J.; Medina, I.; Martínez, M.J.; Carbajo, A. Dual touch and gesture recognition in 4-wire resistive touchscreens. In Proceedings of the IEEE Sensors, Valencia, Spain, 2-5 November 2014.

170. Chi, H.S.; Crockett, T.W.; Makley, A.V. Resistive Scanning Grid Touch Panel. U.S. Patent 7,492,358 B2, 17 February 2009.

171. Wu, C.K.; Wu, M.T. Matrix Resistive Touch Device. U.S. Patent 2010/0164899 A1, 1 July 2010.

172. Fang, W.X. Simultaneous Multiple Location Touch Systems. U.S. Patent 8,310,464 B2, 13 November 2012.

173. An, J.S.; Han, S.H.; Park, K.B.; Kim, J.E.; Ye, J.H.; Lee, S.H.; Jeong, J.Y.; Kim, J.S.; Baek, K.H.; Chung, K.S.; et al. Multi-Way Interactive Capacitive Touch System with Palm Rejection of Active Stylus for 86" Touch Screen Panels. In Proceedings of the IEEE International Solid-State Circuits Conference, San Francisco, CA, USA, 11-15 February 2018; pp. 182-183.

174. Kim, C.; Lee, D.S.; Kim, J.H.; Kim, H.B.; Shin, S.R.; Jung, J.H.; Song, I.H.; Jang, C.S.; Kwon, K.S.; Kim, S.H.; et al. Advanced In-cell Touch Technology for Large Sized Liquid Crystal Displays. Dig. Tech. Pap. Int. Symp. SID 2015, 46, 895-898. [CrossRef]

175. Takahashi, S.; Lee, B.J.; Koh, J.H.; Saito, S.; You, B.H.; Kim, N.D.; Kim, S.S. Embedded Liquid Crystal Capacitive Touch Screen Technology for Large Size LCD Applications. Dig. Tech. Pap. Int. Symp. SID 2009, 40, 563-566. [CrossRef]

176. Park, H.S.; Kim, Y.J.; Han, M.K. Touch-Sensitive Active-Matrix Display with Liquid Crystal Capacitance Detector Arrays. Jpn. J. Appl. Phys. 2010, 49, O3CC01. [CrossRef]

177. Walker, G.; Fihn, M. LCD In-Cell Touch. Inf. Disp. 2010, 3, 8-14. [CrossRef]

178. Lee, S.H.; An, J.S.; Hong, S.K.; Kwon, O.K. In-cell Capacitive Touch Panel Structures and Their Readout Circuits. In Proceedings of the International Workshop on Active-Matrix Flatpanel Displays and Devices, Kyoto, Japan, 6-8 July 2016; pp. 258-261.

179. Chen, Y.; Geng, D.; Jang, J. Integrated Active-Matrix Capacitive Sensor Using a-IGZO TFTs for AMOLED. IEEE J. Electron Devices Soc. 2018, 6, 214-218. [CrossRef]

180. 3M, Dispersive Signal Touch Technology. Available online: https://multimedia.3m.com $/ \mathrm{mws} / \mathrm{media} / 443866 \mathrm{O} / 3 \mathrm{mtm}-$ microtouch-system-sct2270dx-technology-profile.pdf (accessed on 23 April 2021).

181. Hwang, T.H.; Cui, W.H.; Yang, I.S.; Kwon, O.K. A highly area-efficient controller for capacitive touch screen panel systems. IEEE Trans. Consum. Electron. 2010, 56, 1115-1122. [CrossRef]

182. Luo, C.; Borkar, M.A.; Redfern, A.J.; McClellan, J.H. Compressive sensing for sparse touch detection on capacitive touch screens. IEEE J. Emerg. Sel. Topics Circuits Syst. 2012, 2, 639-648. [CrossRef]

183. Li, H.; Wei, Y.; Li, H.; Young, S.; Convey, D.; Lewis, J.; Maniar, P. Multitouch Pixilated Force Sensing Touch Screen. Dig. Tech. Pap. Int. Symp. SID 2009, 40, 455-458. [CrossRef]

184. Hwang, S.; Bianchi, A.; yun Wohn, K. MicPen: Pressure-Sensitive Pen Interaction Using Microphone with Standard Touchscreen. In Proceedings of the Extended Abstracts of the CHI Conference on Human Factors in Computing Systems, Austin, TX, USA, 5-10 May 2012; pp. 1847-1852. 
185. Kim, H.K.; Lee, S.; Yun, K.S. Capacitive tactile sensor array for touch screen application. Sens. Actuator. A Phys. $2011,165,2-7$. [CrossRef]

186. Reynolds, K.; Shepelev, P.; Graf, A. Touch and Display Integration with Force. Dig. Tech. Pap. Int. Symp. SID 2016, 47, 617-620. [CrossRef]

187. Lee, K.H.; Nam, S.P.; Lee, J.H.; Choi, M.; Ko, H.J.; Byun, S.H.; Lee, J.C.; Lee, Y.H.; Rhee, Y.C.; Choi, Y.K.; et al. A Noise-Immune Stylus Analog Front-End Using Adjustable Frequency Modulation and Linear Interpolating Data Reconstruction for Both Electrically Coupled Resonance and Active Styluses. In Proceedings of the IEEE International Solid-State Circuits Conference, San Francisco, CA, USA, 11-15 February 2018, pp. 184-185.

188. Ko, S.; Shin, H.; Lee, J.; Jang, H.; So, B.C.; Yun, I.; Lee, K. Low Noise Capacitive Sensor for Multi-touch Mobile Handset's Applications. In Proceedings of the IEEE Asian Solid-State Circuits Conference, Beijing, China, 8-10 November 2010.

189. Yang, I.S.; Kwon, O.K. A touch controller using differential sensing method for on-cell capacitive touch screen panel systems. IEEE Trans. Consum. Electron. 2011, 57, 1027-1032. [CrossRef]

190. Kim, K.D.; Byun, S.H.; Choi, Y.K.; Baek, J.H.; Cho, H.H.; Park, J.K.; Ahn, H.Y.; Lee, C.J.; Cho, M.S.; Lee, J.H.; et al. A Capacitive Touch Controller Robust to Display Noise for Ultrathin Touch Screen Displays. In Proceedings of the IEEE International Solid-State Circuits Conference, San Francisco, CA, USA, 19-23 February 2012.

191. Yang, J.H.; Park, S.H.; Choi, J.M.; Kim, H.S.; Park, C.B.; Ryu, S.T.; Cho, G.H. A highly noise-immune touch controller using filtered-delta-integration and a charge-interpolation technique for 10.1-inch capacitive touch-screen panels. In Proceedings of the IEEE International Solid-State Circuits Conference, San Francisco, CA, USA, 17-21 February 2013; pp. 390-391.

192. Seo, J.; Nam, H. Low power and low noise shift register for in-cell touch display applications. IEEE J. Electron Devices Soc. 2018, 6, 726-732. [CrossRef]

193. Miura, N.; Dosho, S.; Tezuka, H.; Miki, T.; Fujimoto, D.; Kiriyama, T.; Nagata, M. A 1 mm Pitch $80 \times 80$ Channel 322 Hz Frame-Rate Multitouch Distribution Sensor With Two-Step Dual-Mode Capacitance Scan. IEEE J. Solid-State Circuits 2015, 50, 2741-2749. [CrossRef]

194. Shin, H.; Ko, S.; Jang, H.; Yun, I.; Lee, K. A 55 dB SNR with 240 Hz frame scan rate mutual capacitor $30 \times 24$ touch-screen panel read-out IC using code-division multiple sensing technique. In Proceedings of the IEEE International Solid-State Circuits Conference, San Francisco, CA, USA, 17-21 February 2013; pp. 388-389.

195. Hamaguchi, M.; Nagao, A.; Miyamoto, M. 12.3 A 240 Hz-reporting-rate $143 \times 81$ mutual-capacitance touch-sensing analog front-end IC with $37 \mathrm{~dB}$ SNR for $1 \mathrm{~mm}$-diameter stylus. In Proceedings of the IEEE International Solid-State Circuits Conference, San Francisco, CA, USA, 9-13 February 2014; pp. 214-215.

196. Heo, S.; Ma, H.; Song, J.; Park, K.; Choi, E.H.; Kim, J.J.; Bien, F. 72 dB SNR, 240 Hz frame rate readout IC with differential continuous-mode parallel architecture for larger touch-screen panel applications. IEEE Trans. Circuits Syst. I Reg. Pap. 2016, 63, 960-971. [CrossRef]

197. Park, J.E.; Lim, D.H.; Jeong, D.K. A Reconfigurable 40-to-67 dB SNR, 50-to-6400 Hz Frame-Rate, Column-Parallel Readout IC for Capacitive Touch-Screen Panels. IEEE J. Solid-State Circuits 2014, 49, 2305-2318. [CrossRef]

198. An, J.S.; Ra, J.H.; Kang, E.; Pertijs, M.A.P.; Han, S.H. 28.1 A Capacitive Touch Chipset with 33.9 dB Charge- Overflow Reduction Using Amplitude-Modulated Multi-Frequency Excitation and Wireless Power and Data Transfer to an Active Stylus. In Proceedings of the IEEE International Solid-State Circuits Conference, San Francisco, CA, USA, 16-20 February 2020; pp. 430-431.

199. Lin, C.L.; Li, C.S.; Chang, Y.M.; Lin, T.C.; Chen, J.F.; Lin, U.C. Pressure Sensitive Stylus and Algorithm for Touchscreen Panel. J. Disp. Technol. 2013, 9, 17-23. [CrossRef]

200. Bishop, C. Pattern Recognition and Machine Learning; Springer: New York, NY, USA, 2007.

201. Goodfellow, I.; Bengio, Y.; Courville, A. Deep Learning; MIT Press: Cambridge, MA, USA, $2016 . \quad$ Available online: http: //www.deeplearningbook.org (accessed on 23 April 202 ).

202. Ioffe, S.; Szegedy, C. Batch Normalization: Accelerating Deep Network Training by Reducing Internal Covariate Shift. In Proceedings of the International Conference on Machine Learning, Lille, France, 7-9 July 2015; pp. 448-456.

203. Seol, K.H.; Park, S.; Nam, H. A Contact-Based Data Communication Technique Using Capacitive Touch Screen Panel and Support Vector Machine Classifier. IEEE Access 2019, 7, 178596-178604. [CrossRef]

204. Ma, H.; Liu, Z.; Heo, S.; Lee, J.; Na, K.; Jin, H.B.; Jung, S.; Park, K.; Kim, J.J.; Bien, F. On-Display Transparent Half-Diamond Pattern Capacitive Fingerprint Sensor Compatible With AMOLED Display. IEEE Sens. J. 2016, 16, 8124-8131. [CrossRef]

205. Seo, W.; Pi, J.E.; Cho, S.H.; Kang, S.Y.; Ahn, S.D.; Hwang, C.S.; Jeon, H.S.; Kim, J.U.; Lee, M. Transparent Fingerprint Sensor System for Large Flat Panel Display. Sensors 2018, 18, 293. [CrossRef]

206. Yang, W.; Zhang, X.; Tian, Y.; Wang, W.; Xue, J.H.; Liao, Q. Deep learning for single image super-resolution: A brief review. IEEE Trans. Multimed. 2019, 21, 3106-3121. [CrossRef]

207. Wang, Z.; Chen, J.; Hoi, S.C. Deep learning for image super-resolution: A survey. IEEE Trans. Pattern Anal. Mach. Intell. 2021, in press. [CrossRef] 